\title{
Seizures and epilepsy in patients with ischaemic stroke
}

\author{
Johann Philipp Zöllner ${ }^{1,2^{*}}$ (D) Friedhelm C. Schmitt ${ }^{3}$, Felix Rosenow ${ }^{1,2}$, Konstantin Kohlhase $^{1,2}$, Alexander Seiler ${ }^{1}$, \\ Adam Strzelczyk ${ }^{1,2^{*}}$ and Hermann Stefan ${ }^{4^{*}}$
}

\begin{abstract}
Background: With the increased efficacy of stroke treatments, diagnosis and specific treatment needs of patients with post-stroke seizures (PSS) and post-stroke epilepsy have become increasingly important. PSS can complicate the diagnosis of a stroke and the treatment of stroke patients, and can worsen post-stroke morbidity. This narrative review considers current treatment guidelines, the specifics of antiseizure treatment in stroke patients as well as the stateof-the-art in clinical and imaging research of post-stroke epilepsy. Treatment of PSS needs to consider indications for antiseizure medication treatment as well as individual clinical and social factors. Furthermore, potential interactions between stroke and antiseizure treatments must be carefully considered. The relationship between acute recanalizing stroke therapy (intravenous thrombolysis and mechanical thrombectomy) and the emergence of PSS is currently the subject of an intensive discussion. In the subacute and chronic post-stroke phases, important specific interactions between necessary antiseizure and stroke treatments (anticoagulation, cardiac medication) need to be considered. Among all forms of prevention, primary prevention is currently the most intensively researched. This includes specifically the repurposing of drugs that were not originally developed for antiseizure properties, such as statins. PSS are presently the subject of extensive basic clinical research. Of specific interest are the role of post-stroke excitotoxicity and blood-brain barrier disruption for the emergence of PSS in the acute symptomatic as well as late ( $>1$ week after the stroke) periods. Current magnetic resonance imaging research focussing on glutamate excitotoxicity as well as diffusion-based estimation of blood-brain barrier integrity aim to elucidate the pathophysiology of seizures after stroke and the principles of epileptogenesis in structural epilepsy in general. These approaches may also reveal new imaging-based biomarkers for prediction of PSS and post-stroke epilepsy.
\end{abstract}

Conclusion: PSS require the performance of individual risk assessments, accounting for the potential effectiveness and side effects of antiseizure therapy. The use of intravenous thrombolysis and mechanical thrombectomy is not associated with an increased risk of PSS. Advances in stroke imaging may reveal biomarkers for PSS.

Keywords: Cerebral ischaemia, Mortality, Antiepileptic drug, Anticonvulsants, Thrombolysis, Mechanical thrombectomy, Biomarkers, Prognosis

\footnotetext{
*Correspondence: zoellner@med.uni-frankfurt.de

1 Department of Neurology and Epilepsy Center Frankfurt Rhine-Main,

Center of Neurology and Neurosurgery, Goethe-University Frankfurt,

Schleusenweg 2-16, 60528 Frankfurt am Main, Germany

${ }^{4}$ Department of Neurology - Biomagnetism, University Hospital Erlangen, Erlangen, Germany

Full list of author information is available at the end of the article
}

\begin{abstract}
Background
Improvements in stroke treatment and rehabilitation have reduced stroke-associated mortality rates in the last decades. However, this improvement has been accompanied by an increased prevalence and relevance of poststroke seizures (PSS), which manifest in approximately $5-7 \%$ of ischaemic stroke survivors each year $[1,2]$ and can worsen post-stroke prognosis. The PSS risk is higher
\end{abstract}

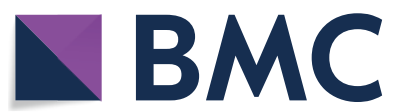

(c) The Author(s) 2021. Open Access This article is licensed under a Creative Commons Attribution 4.0 International License, which permits use, sharing, adaptation, distribution and reproduction in any medium or format, as long as you give appropriate credit to the original author(s) and the source, provide a link to the Creative Commons licence, and indicate if changes were made. The images or other third party material in this article are included in the article's Creative Commons licence, unless indicated otherwise in a credit line to the material. If material is not included in the article's Creative Commons licence and your intended use is not permitted by statutory regulation or exceeds the permitted use, you will need to obtain permission directly from the copyright holder. To view a copy of this licence, visit http://creativecommons.org/licenses/by/4.0/. 
(10-16\%) in those who experience primary intracerebral, subarachnoid, or subdural haemorrhage [3-5]. PSS treatment options, including personalised medical approaches, are currently being investigated from a variety of perspectives [6].

Here, we discuss (1) the current indications and therapy for PSS; (2) prevention strategies and personalised therapeutic concepts; and (3) new research approaches.

\section{Current indications and drug treatment options} Indications for antiseizure medication therapy in stroke

Seizures that occur within 7 days of any acute lesion event, such as stroke, traumatic brain injury, or brain surgery, are referred to as acute-symptomatic seizures (ASS) or "early" seizures, whereas all subsequent seizures are termed "late" seizures (LS) [7]. This distinction is based on pathophysiological reasoning and clinical observations. ASS are considered a correlate of the homeostatic disturbances in acute brain injury and thus do not per se equate epilepsy. LS, however, are presumed to occur spontaneously in a brain that is structurally predisposed to seizure generation. According to most studies, LS in stroke survivors are associated with a high risk $(>70 \%)$ of seizure recurrence, higher than after ASS [8]. Thus a single, unprovoked, LS results in diagnosis of post-stroke epilepsy (PSE) according to the current epilepsy definition established by the International League Against Epilepsy (ILAE) [9, 10], which set a threshold of $>60 \%$ recurrence risk within 10 years [10].

The American Heart Association (AHA)/American Stroke Association (ASA) guidelines do not recommend the primary preventive administration of anti-seizure medication (ASM) after stroke, even following haemorrhagic stroke, which has a higher risk for PSS compared with other stroke types [11-13]. In addition, ASM therapy is generally not recommended following ASS [12]. However, ASM therapy is generally recommended as a secondary prevention measure in established PSE; or in any case of status epilepticus (SE) [10]. Some borderline cases may warrant ASM therapy, which then must be individually determined: ASS following cerebral infarction with haemorrhagic transformation and the occurrence of multiple ASS within 24 hours can indicate short-term ASM treatment (over one month), which might reduce the risk of later seizures and PSE [14]. If ASS is associated with primary cerebral haemorrhage or cerebral venous sinus thrombosis with motor deficits, ASM treatment over several weeks can be considered, although insufficient evidence exists to support any general recommendations $[15,16]$. The European Stroke Organization (ESO) guidelines [3] recommend the discontinuation of ASM administered after an ASS when the acute (stroke unit) phase has passed and the patient is transferred, but the authors caution that the current level of evidence regarding almost all recommendations for PSS treatment is very low. In consequence, treatment initiation for PSS should consider infarct and seizure characteristics, comorbidities, ASM adherence, medication tolerance, and interactions, among other factors.

Well-established risk factors for both ASS and LS following ischaemic stroke include stroke severity, cortical localisation, younger age, and haemorrhagic transformation [17]. An analysis of 135,117 patients with ischaemic stroke showed that ASS risk is associated with higher National Institutes of Health Stroke Scale (NIHSS) scores on admission [18]. While relatively mild strokes $(\mathrm{NIHSS}<3)$ were associated with an ASS risk of $0.6 \%$, the most severe stroke (NIHSS > 31) carried an ASS risk of $9 \%$; with the odds of ASS increasing by $9.2 \%$ for every additional NIHSS point [18]. Non-neurological infections and a low premorbid functional level also increased the risk for ASS [18]. Risk scales can be used to aid decisionmaking, such as the Post-Stroke Epilepsy Risk Scale (PoSERS: Sensitivity 70\%, Specificity 99.6\%) or the SeLECT Score (Severity of stroke, large-artery atherosclerotic aetiology, early seizures, cortical involvement, territory of middle cerebral artery involvement; Sensitivity $18.2 \%$, Specificity $96.7 \%$, for cutoff at $\geq 6$ points) [19-21]. If an unprovoked LS occurs, the patient should be informed of the recurrence risk, and ASM therapy should be recommended. Individual treatment recommendations should be thoroughly discussed with the patient, with consideration for current research findings [3] and personalised medical factors such as vocational and driving licence status or e.g. risk of seizure-associated falls. An exclusively non-severe seizure presentation (e.g. no focal impaired-awareness seizures, no focal-to-bilateral tonicclonic seizures, and a low risk of injury during seizures) may not require ASM therapy. As the risk of neurological damage following post-stroke SE is $2-3$ times higher compared to non-seizure patients (among 31 patients with SE, 15 patients died within 10 years, including 5 that died during an SE event), long-term therapy is necessary after post-stroke SE [22].

In the pre-hospital to emergency room phase, the differential diagnosis of acute cerebral infarction and postictal Todd's paresis can be challenging if preceding positive motor seizure symptoms are not observed. In one study of 539 patients undergoing thrombolysis, 11 were retrospectively determined to have had Todd's paresis rather than stroke [23]. Seizure-associated stroke mimics account for $85 \%$ of all mimics that receive acute stroke treatment, such as thrombolysis [24]. This diagnostic uncertainty can be consequential for therapy: Misdiagnosing stroke as seizure can delay time-critical recanalization therapy. The opposite risk associated with 
thrombolysis in patients with stroke-mimicing seizures however is probably much lower; the available studies on seizure-related stroke mimics did not report serious thrombolysis-related adverse reactions [24].

The differential diagnosis is further complicated by very-early "stroke-onset" seizures. Pre-existing neurological deficits must also be evaluated in the assessment of potential LS sequelae in those with a previous stroke.

\section{Choice of antiseizure medication in the treatment of post-stroke seizures}

The long-held assumption that most patients with PSE can successfully be treated using ASM monotherapy [25] has recently been challenged [26]. This underscores the importance of thoughtful ASM selection in stroke patients, who tend to be older, especially regarding potential drug interactions. Overall, clinical studies have suggested that new-generation ASM are preferable to first-generation ASM for the treatment of PSE due to improved tolerability and reduced interactions with other drugs [27]. Among the newer ASM, lamotrigine (LTG), levetiracetam (LEV), and lacosamide (LCM) have demonstrated relatively high tolerability and unproblematic interaction profiles in PSE treatment.

LTG shows moderate antiseizure efficacy, is well tolerated, is typically mood-stabilising, has a low interaction potential, and is relatively convenient apart from the necessity of slow dose increases (once-daily administration is possible). Interestingly, LTG is better tolerated in patients with PSS than carbamazepine (CBZ), another liver-metabolized ASM [28]. Recent in-vitro data have demonstrated that the sodium channel blocker LTG acts as class IB antiarrhythmic agent at therapeutic serum levels. Possible proarrhythmogenic properties prompted addition of a warning to the label by the United States Food and Drug Administration (FDA) [29]. In the absence of clinical data, the ILAE pragmatically recommends to obtain an electrocardiogram (ECG) before start of LTG in those with known cardiac disease, cardiovascular risk factors and those above 60 years of age to rule out relevant cardiac conduction abnormalities [29]. Most stroke patients fall into these categories, however, a thorough cardiologic work-up including routine and in some cases long-term ECG is part of standard-of-care in stroke patients, which increases the likelihood that pre-existing cardiac conditions have already been identified. An ECG should be repeated in those with cardiac disease at target dose.

LEV is associated with high antiseizure efficacy, a low interaction potential, and can be administered in an intravenous formulation for the rapid achievement of effective serum concentrations and use in patients with impaired swallowing. Adverse reactions following LEV administration occur in fewer than $10 \%$ of patients (irritability and mood swings). In a prospective open-label study on LEV treatment of late post-stroke seizures [30], $77.1 \%$ of patients remained seizure-free for one year. Four patients (11.4\%) discontinued LEV due to intolerable side effects (tiredness in one patient and aggressive behaviour in 3 patients) [30, 31]. In another prospective randomized open-label study, no significant difference in effectiveness was observed between LEV and controlled-release CBZ, but LEV was better tolerated [32].

LCM is generally well-tolerated and effective in patients with epilepsy of cerebrovascular etiology [33] and intravenously administered LCM showed high efficacy and tolerability in non-convulsive SE (NCSE) following stroke in patients older than 70 years [34].

Gabapentin (GBP) likely has lower antiseizure efficacy and requires multiple daily doses but has a low interaction potential. Of note, GBP carries the risk of dizziness, vertigo and altered mental status in elderly patients, especially with higher daily doses [35].

Head-to-head comparisons from randomised-controlled trials are not available specifically for efficacy in PSE. However, the STEP-ONE trial compared LEV, LTG, and controlled-release $\mathrm{CBZ}$ as initial monotherapy for focal epilepsy in older individuals using a randomised setting [36]. The trial showed that the one-year retention of LEV was higher than that of CBZ due to better tolerability, whereas LTG retention was intermediate but did not differ significantly from either comparator [36]. In the recently published SANAD II study, LTG showed a better 12-month seizure remission rate than both LEV and zonisamide following the initial monotherapy of focal epilepsies [37].

Eslicarbazepine (ESL), LCM, oxcarbazepine (OXC), perampanel (PER), and zonisamide are currently underinvestigated in PSE [38-40]. An exploratory pilot study showed that LCM was relatively effective in patients with epilepsy with cerebrovascular aetiologies, with high tolerability, assuming that appropriate care is taken regarding contraindications (most importantly, certain cardiac conduction disorders). Data for monotherapies suggested both a better antiseizure efficacy and favourable pharmacokinetic profile (i.e. fewer interactions and less negative influence on lipid concentrations) for LCM in comparison to CBZ [33]. Publications on the clinical effectiveness and tolerability of ASM for PSE treatment are summarised in Table 1.

CBZ, phenytoin (PHT), and valproate (VPA) are not first-line ASM among older patients due to their lower tolerability and considerable interaction profiles. Of particular concern, a marked reduction was observed for direct-acting oral anticoagulant (DOAC) serum concentrations following CBZ and PHT administration, and 
Table 1 Publications reporting the clinical efficacy and tolerability of antiseizure medication for treatment of post-stroke epilepsy

\begin{tabular}{|c|c|c|c|c|c|c|c|c|}
\hline Author & Study design & $\begin{array}{l}\text { Participants } \\
\text { (n) }\end{array}$ & Age (years) & $\begin{array}{l}\text { Medication } \\
(\mathrm{mg})\end{array}$ & Period & $\begin{array}{l}\text { Seizure } \\
\text { recurrence }\end{array}$ & Tolerability & Limitations \\
\hline $\begin{array}{l}\text { Alvarez-Sabin } \\
\text { et al. [38] }\end{array}$ & $\begin{array}{l}\text { Prospective } \\
\text { Observational }\end{array}$ & $\begin{array}{l}48 \text { ischaemic } \\
23 \text { haemor- } \\
\text { rhagic }\end{array}$ & 63.9 & $\begin{array}{l}\text { GBP } \\
900-1800 \mathrm{mg}\end{array}$ & 30 months & $18 \%$ & $\begin{array}{l}\text { Adverse events } \\
38 \% ; \\
\text { discontinued } \\
3 \%\end{array}$ & SN, NR, NP \\
\hline Gilad et al. [28] & $\begin{array}{l}\text { Prospective } \\
\text { Randomised }\end{array}$ & 64 ischaemic & $\begin{array}{l}\text { LTG } 67.2 \\
\text { CBZ } 67.7\end{array}$ & $\begin{array}{l}\text { LTG 25-200 mg } \\
\text { CBZ 100- } \\
600 \text { mg }\end{array}$ & 12 months & $\begin{array}{l}\text { LTG 28\% } \\
\text { CBZ 56\% }\end{array}$ & $\begin{array}{l}\text { Discontinued } \\
\text { LTG 3\%, CBZ } \\
31 \%\end{array}$ & $\mathrm{SN}, \mathrm{NP}, \mathrm{NDB}$ \\
\hline Kutlu et al. [116] & $\begin{array}{l}\text { Prospective } \\
\text { Observational }\end{array}$ & 34 ischaemic & 69.8 & $\begin{array}{l}\text { LEV 1000- } \\
2000 \text { mg }\end{array}$ & 17.7 months & $18 \%$ & $\begin{array}{l}\text { Discontinued } \\
21 \% \text {; stopped } \\
3 \%\end{array}$ & SN, NR, NP \\
\hline $\begin{array}{l}\text { Belcastro et al. } \\
\text { [30] }\end{array}$ & $\begin{array}{l}\text { Prospective } \\
\text { Observational }\end{array}$ & 35 ischaemic & 71.9 & $\begin{array}{l}\text { LEV 1000- } \\
2000 \text { mg }\end{array}$ & 18 months & $9 \%$ & $\begin{array}{l}\text { Discontinued } \\
11 \%\end{array}$ & $\mathrm{SN}, \mathrm{NR}, \mathrm{NP}$ \\
\hline $\begin{array}{l}\text { Consoli et al. } \\
\text { [32] }\end{array}$ & $\begin{array}{l}\text { Prospective } \\
\text { Randomised }\end{array}$ & $\begin{array}{l}79 \text { ischaemic } \\
27 \text { haemor- } \\
\text { rhagic }\end{array}$ & $\begin{array}{l}\text { LEV } 74.1 \\
\text { CBZ } 54\end{array}$ & $\begin{array}{l}\text { LEV } 52 \\
\text { CBZ } 54\end{array}$ & 13,5 months & $\begin{array}{l}\text { LEV 6\% } \\
\text { CBZ 15\% }\end{array}$ & $\begin{array}{l}\text { Discontinued } \\
\text { LEV 33\%, CBZ } \\
39 \%\end{array}$ & $\mathrm{SN}, \mathrm{NP}, \mathrm{NDB}$ \\
\hline $\begin{array}{l}\text { Tanaka and } \\
\text { Ihara [117] }\end{array}$ & $\begin{array}{l}\text { Retrospective } \\
\text { Observational }\end{array}$ & $\begin{array}{l}69 \text { ischaemic } \\
43 \text { haemor- } \\
\text { rhagic }\end{array}$ & 72.3 & $\begin{array}{l}23 \text { VPA, } 22 \text { PHT } \\
15 \text { CBZ }\end{array}$ & 12 months & $\begin{array}{l}\text { VPA 48\% } \\
\text { PHT 18\% } \\
\text { CBZ 13\% }\end{array}$ & - & $\begin{array}{l}\text { SN, mono- and } \\
\text { polytherapy }\end{array}$ \\
\hline $\begin{array}{l}\text { Huang et al. } \\
\text { [118] }\end{array}$ & $\begin{array}{l}\text { Retrospective } \\
\text { Observational }\end{array}$ & $\begin{array}{l}1729 \text { ischaemic } \\
1893 \text { haemor- } \\
\text { rhagic }\end{array}$ & 60.3 & $\begin{array}{l}\text { PHT } 2507 \\
\text { VPA } 712 \\
\text { CBZ } 157 \\
\text { Newer ASM } \\
246\end{array}$ & $\begin{array}{l}100 \\
\text { person - } \\
\text { months }\end{array}$ & $\begin{array}{l}\text { PHT 1.05\% (ER } \\
\text { visits) } \\
\text { VPA 0.7\% } \\
\text { CBZ 0.4\% } \\
\text { Newer ASM } \\
0.38 \%\end{array}$ & - & $\begin{array}{l}\text { Seizure in } \\
\text { first } 3 \text { months } \\
\text { excluded }\end{array}$ \\
\hline Sales et al. [39] & $\begin{array}{l}\text { Retrospective } \\
\text { Observational }\end{array}$ & $\begin{array}{l}76 \text { PSE } \\
1590 \mathrm{EPI}^{*}\end{array}$ & $\begin{array}{l}\text { PSE } 63 \\
\text { EPI } 61.4\end{array}$ & $\begin{array}{l}\text { ESL/PSE } 887 \\
\text { ESL/EPI } 983\end{array}$ & 12 months & $\begin{array}{l}51.4 \% \\
68.3 \%\end{array}$ & $\begin{array}{l}\text { Adverse events } \\
36 \% \text { versus } \\
35.8 \%\end{array}$ & $\begin{array}{l}\text { Multicentric, } \\
\text { differences } \\
\text { between cohorts }\end{array}$ \\
\hline
\end{tabular}

Publications reporting the clinical effectiveness and tolerance for anticonvulsants used for the treatment of PSE, modified after Tanaka and Ihara [117]. Abbreviations: ASM: anti-seizure medication, CBZ: carbamazepine, EPI: epilepsy not associated with stroke (* with differences in age, length of preceding epilepsy treatment), ER: emergency room, ESL: eslicarbazepine, GBP: gabapentin, LEV: levetiracetam, LTG: lamotrigine, NDB: not double-blind, NP: no placebo, NR: non-randomised, PHT: phenytoin, PSE: post-stroke epilepsy, SN: small number of patients; VPA: valproate

CBZ and ESL may inhibit simvastatin [41-44]. CBZ, $\mathrm{OXC}$, and ESL can also cause hyponatraemia, particularly in older people $[45,46]$.

A risk-based therapeutic strategy for ASS or LS is schematically reproduced in Fig. 1, based on the strategy described by Zelano [47].

\section{Interrelation of therapies for stroke and post-stroke epilepsy} Thrombolysis, mechanical thrombectomy and post-stroke seizures

Does thrombolysis increase the risk of PSS? Thrombolysis has been suggested as a potential PSS risk factor since the thrombolytic agent recombinant tissue plasminogen activator (rt-PA) can have neurotoxic effects on the infarcted brain $[48,49]$. Successful reperfusion itself is a possible ASS-generating mechanism.

Initially, case reports suggested that ASS during recanalisation resulted in neurological improvements [50]; since then, further results have supported the notion of reperfusion as seizure generator [51]. Brigo et al. [52] showed that intravenous (i.v.) rt-PA administration (odds ratio [OR]: 2.26) independently increases the risk of ASS. Alvarez et al. [48] described frequent ASS following thrombolysis, associated with a worse prognosis.

Thrombolysis emerged as an independent risk factor also for LS in a population-based, retrospective cohort study [53]. Naylor et al. [54] observed an increase in LS occurrence as late as 24 months after thrombolysis. Analysis of various treatment groups (i.v. rt-PA, intra-arterial thrombolysis [IAT], or both) showed that all reperfusion therapies were associated with a similar increase in seizure frequency, compared with conservative stroke treatments (i.v. rt-PA corrected OR [cOR]: 3.7, 95\% confidence interval $[\mathrm{CI}]: 1.8-7.4, p<0.001$; IAT cOR: 5.5 , 95\% CI 2.1-14.3, $p<0.001$; IAT + i.v. rt-PA cOR: 3.4, 95\% CI 0.98-11.8, $p=0.05$ ) [54]. Castro-Apolo et al. found a similar effect on prognosis in those treated with i.v. rt-PA who had LS [55]. Brondani et al. also showed that PSS are an independent risk factor for worse prognosis following thrombolysis for stroke [56]. In this study [56], neurological deficits following thrombolysis and haemorrhagic transformation were independent risk factors for PSS. 


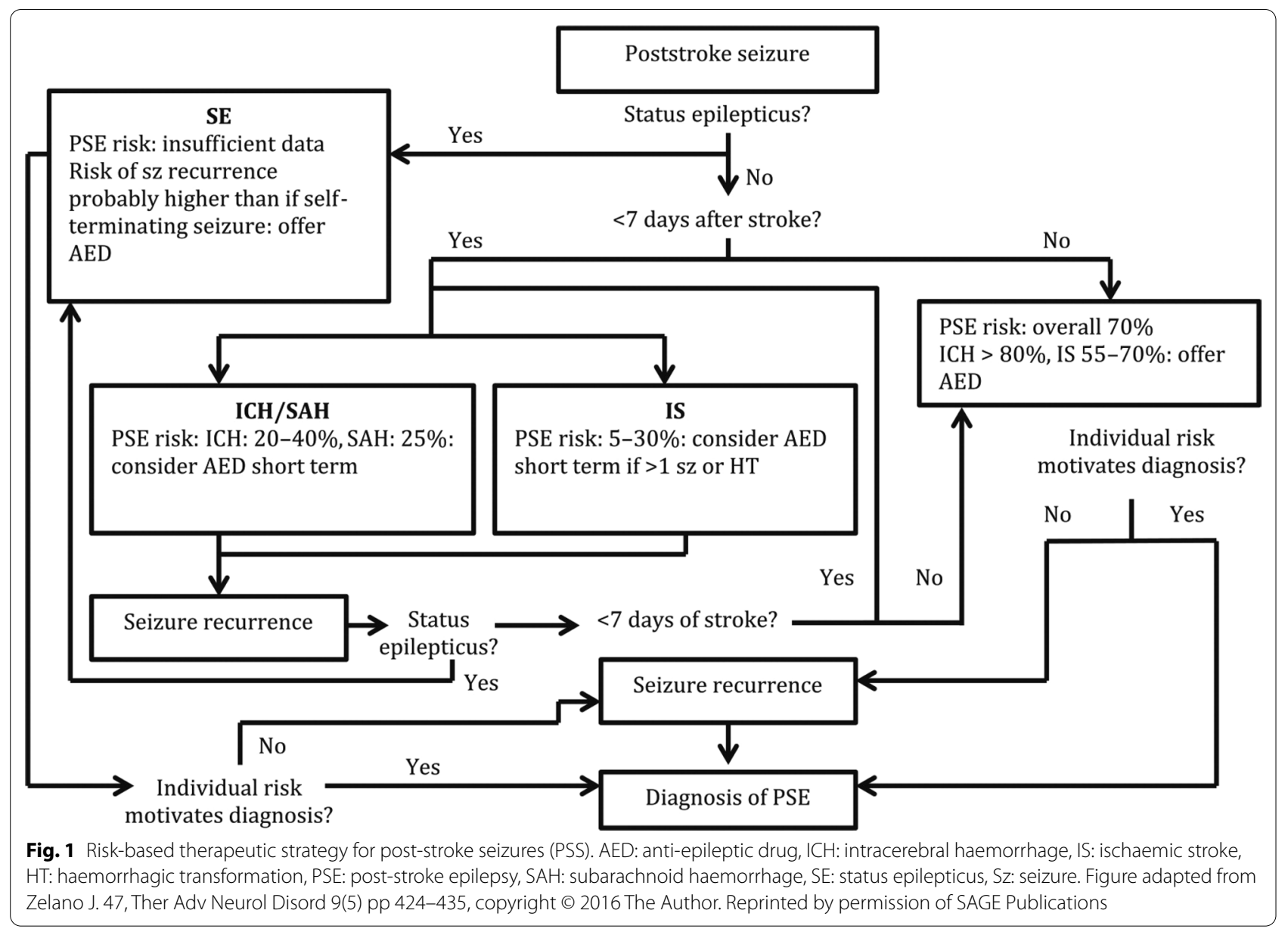

Despite successful reperfusion and potential neurotoxicity being mechanisms for PSS generation, more recent, larger studies have uniformly demonstrated that recanalization overall is not associated with an increased risk for either ASS or LS. In a recent meta-analysis, seizure frequency (ASS 3.14\%, LS 6.7\%) after treatment with i.v. rt-PA, mechanical thrombectomy (MT), or both, was similar to the incidence in large, unselected patient databases, and the pooled analysis did not find significantly increased odds of PSS in those with rt-PA or MT [57, 58]. A meta-analysis of over 30 studies performed by Gasparini [59] indicated a PSE prevalence of 7\%. Cortical lesions (OR: 3.58, 95\% CI 2.35-5.46, $p<0.001$ ), haemorrhagic components (OR: 2.47, 95\% CI 1.68-3.64, $p<0.001$ ), ASS (OR: $4.88,95 \%$ CI 3.08-7.72, $p<0.001$ ), and young age (difference in means with/without PSE: 2.97 years, $95 \%$ CI $0.78-5.16, p=0.008$ ) were more often associated with PSE. Therapy with rt-PA was again not identified as an independent risk factor for PSS. Consistently, Keller et al. [60] could not determine an influence for i.v. rt-PA on PSS frequency. A newer analysis by Zöllner et al. of 13,356 patients who were treated with thrombolysis for ischaemic stroke did not show a higher incidence of early seizures compared to not thrombolysed patients ( $1.5 \%$ vs. $1.8 \%, p=0.07)$ [18]. In addition, among 1,013 patients who were treated with thrombolysis and MT, early seizure incidence was not higher than with thrombolysis alone (both $1.7 \%, p=1$ ) [61]. The finding that MT does not increase PSS risk was supported by a recent prospective study on 344 patients with ischaemic stroke [51]. De Reuck et al. [62] and Nesselroth et al. [63] even reported that thrombolysis partially prevented PSE, which was attributed to tissue salvage in thrombolysed patients. Kim et al. [64] suggested that rt-PA has a protective effect on brain tissue. In an further study [65] comparing 177 patients treated with i.v. rt-PA to 158 who were not specifically treated, no increase in PSS incidence was attributed to rt-PA [65]. An overview of the studies examining the risk factors for seizure development following thrombolysis can be found in Table 2.

In conclusion, studies of seizure development following recanalisation, thus far, have been somewhat contradictory. The largest studies and meta-analyses however indicate that neither i.v. rt-PA nor (with less certainty) MT 

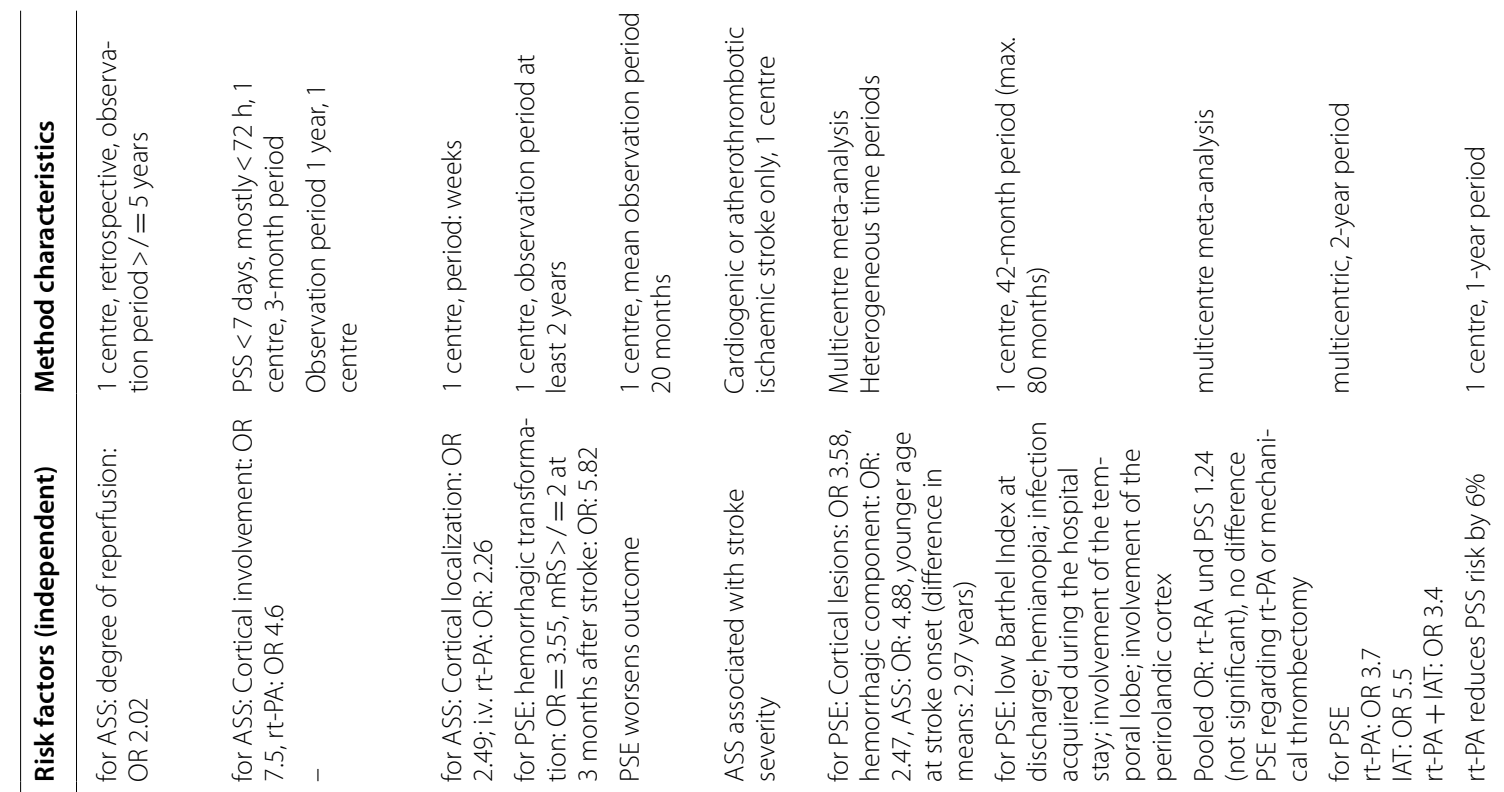

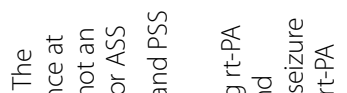

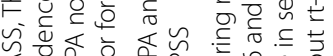

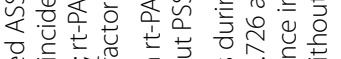

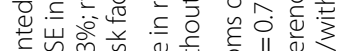

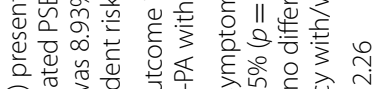

y

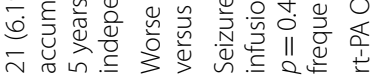

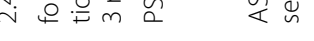
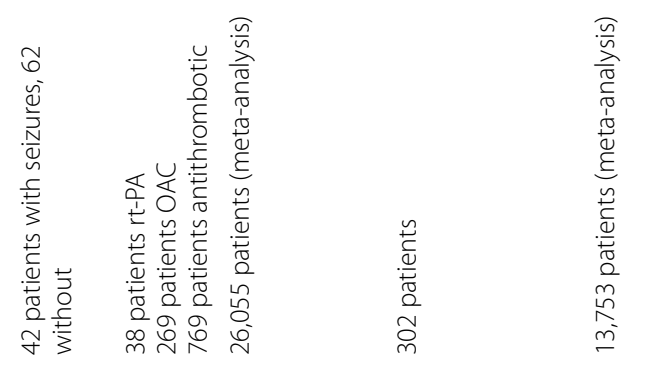

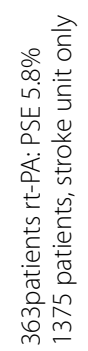

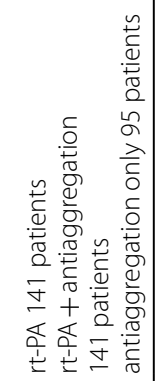




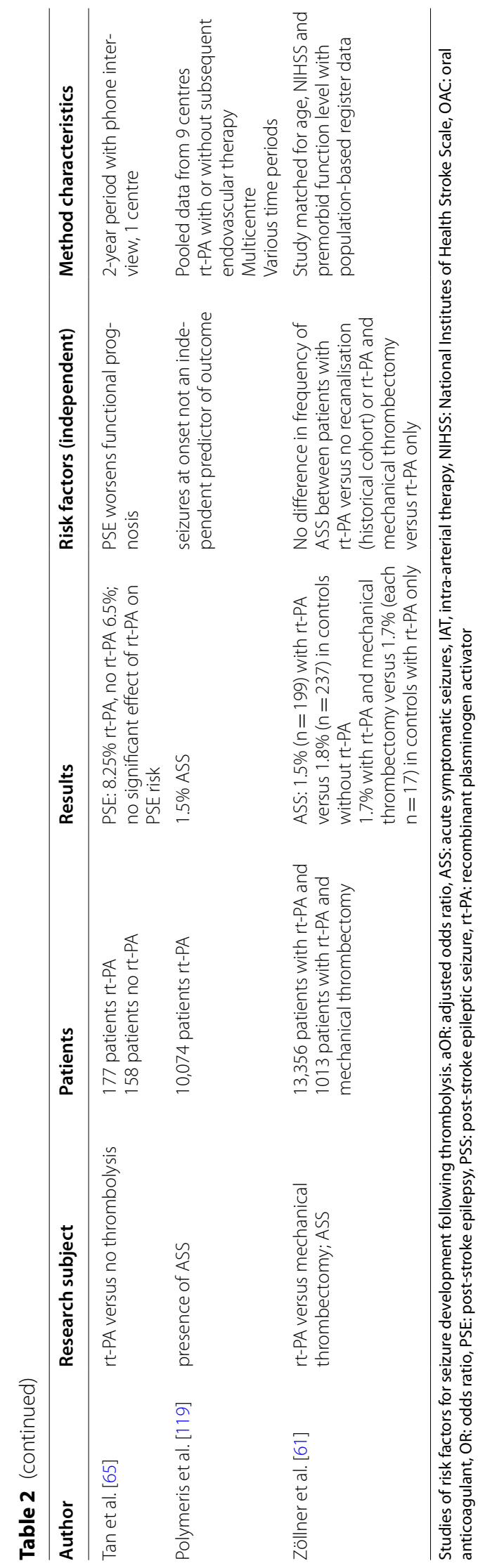


are independent risk factors for ASS or LS when controlling for other known risk factors, such as stroke severity, cortical location and haemorrhagic transformation [57, $59,61]$. The inconsistency of past results can be ascribed to variation in investigation methods and included clinical variables, and small case numbers in single-centre studies. As an inherent methodological limitation of meta-analyses, important clinical variables may not be available at the patient level, precluding the correction for confounders and the overestimation of the effects of recanalisation on PSS risk $[58,66]$. The volume and (cortical) location of successfully reperfused parenchyma as risk factor for ASS generation [51] remains understudied and deems further investigation.

\section{Effects of ASM on coagulation and the cardiovascular system}

The European Heart Rhythm Association (EHRA) published recommendations in 2018 for the use of nonvitamin-K anticoagulants (DOAC) in patients with atrial fibrillation [67]. These suggested that the combination of LEV and DOAC might be problematic, based on considerations of P-glycoprotein (P-gp) function in animal models. Von Oertzen et al. [68] objected to this suggestion, as no clinical evidence of a LEV-DOAC interaction has been reported, and the increased risk of mortality associated with PSE following stroke should be a more serious consideration. Further pharmacogenetic studies have supported this lack-of-interaction $[69,70]$. By contrast, enzyme-inducing ASM, such as CBZ, PHT, phenobarbital, and primidone, can interact significantly with common post-stroke drugs, including anticoagulants, antihypertensives, and statins, with potentially severe risks for stroke patients. The differences in interaction potential between edoxaban, dabigatran, apixaban, and rivaroxaban are summarised by Steffel et al. [67]; of note, certain anti-arrhythmic drugs can exhibit proconvulsant side effects [71].

\section{Primary, secondary, and tertiary prevention of epileptic seizures following stroke}

Epileptic seizures following stroke can lead to the worsening of brain damage, as demonstrated by the results of a study employing diffusion-weighted magnetic resonance imaging (MRI) [72], and the determination of possible preventive measures is of great importance. Primary prevention involves the immediate prevention of seizures following stroke. Secondary prevention refers to the prevention of further seizures following an initial PSS. Tertiary prevention includes seizure recurrence prophylaxis to facilitate medicorehabilitative treatment and modify epileptogenicity after stroke.

\section{Tertiary prevention}

Approaches to tertiary prevention comprise individually optimised rehabilitation and antiseizure therapy. In addition to the indication, selection, and dosing of ASM, potential long-term consequences should be considered. Patients with PSE commonly present with several cardiovascular risk factors, requiring the avoidance of ASM that adversely affect biochemical markers of vascular disease, such as total cholesterol, lipoproteins, C-reactive protein (CRP), and total homocysteine, which may eliminate CBZ, PHT, phenobarbital, and primidone as options according to Mintzer et al. [73]. Chuang et al. [74] reported a significant increase in the intima-media thickness of the common carotid artery (CCA-IMT) with the long-term ( $>2$ years) use of older-generation ASM (CBZ, PHT, and VPA), correlating with use duration. The use of enzyme-inducers, such as CBZ or PHT, was associated with adverse changes in cholesterol, folic acid metabolism, and increased CRP. Patients also showed higher uric acid and total homocysteine levels and higher oxidation markers, such as thiobarbituric acid reactive substances (by-products of lipid re-oxidation). No significant changes in these markers or in the CCA-IMT were observed with LTG monotherapy. However, the average duration of LTG therapy in this study was shorter (5.5 \pm 3.1 years) than of the other medications (CBZ: 13.4 years, PHT: 10.7 years, and VPA: 8.7 years). When comparing CBZ, PHT, and VPA, a particularly strong association with increased high-density lipoprotein cholesterol was observed for CBZ and PHT [75]. This suggests a possible link to the observation that statin therapy can reduce the risk of PSS recurrence, independent of the secondary preventative effect of statins on strokes themselves [17].

\section{Secondary prevention}

The indications for secondary prevention after a single PSS are discussed above. Of note, long-held assumptions that seizure control is easier achievable in PSE compared with focal epilepsy in general [25] have recently been challenged [26].

\section{Primary prevention}

It is worth noting that current guidelines do not recommend primary preventative antiseizure treatment of patients with ischaemic stroke [3, 12]. While primary prevention of PSS and PSE is the subject of extensive research efforts, trials that are adequately powered to guide treatment are still lacking [3]. In practice, primary prevention refers to the exploitation of the additional antiepileptogenic effects of a drug rather than its intended pharmacologic properties. However, heterogeneity among lesions, dosages, and the initiation and 
duration of treatment has made definitive assertions regarding the antiepileptogenic properties of drugs and their potential clinical relevance difficult to achieve, resulting in a lack of translational studies. Klein et al. [76] provided a comprehensive overview of animal studies and clinical data on antiepileptogenic effects of various drugs [76]. Here, we discuss several possibly relevant drugs: Potential antiepileptogenic properties have been ascribed to LEV and GBP [77-79]. Interestingly, the particular nature of existing post-stroke data has led to the discovery of potential antiepileptogenic effects for several drugs apart from their intended use. For example, the antihypertensive drugs losartan and telmisartan, both angiotensin-type 1 receptor (AT1) antagonists, have been proposed to have antiepileptogenic effects based on studies examining the role of the blood-brain barrier (BBB) in epileptogenesis [76]. BBB disruption allows albumin to enter the brain, where it binds transforming growth factor-beta (TGF $\beta$ ) receptors on astrocytes, triggering the release of proinflammatory cytokines, driving epileptogenesis $[80,81]$. AT1 antagonists can inhibit TGF $\beta$ activation and prevent epileptogenesis by blocking Smad 2/3 phosphorylation following $\mathrm{BBB}$ disruption or the direct exposure of the cerebral cortex to albumin [82]. The diuretics thiazide and furosemide have been shown in animal and clinical studies to reduce seizure frequency [83]. Statins reduce the risk of epilepsy-related hospitalisation in patients with cardiovascular disease, whereas several ASM have demonstrated no such effect [84]. In a study by Guo et al., statins were shown to be associated with a reduced risk of PSE [17], a finding that was confirmed by Li et al. [85], who noted that statin use reduced the risk of both ASS and PSE (both $p=0.009$ ). The risk reduction was even stronger with high-dose statin treatment (ASS $p=0.003$, PSE $p=0.006$ ) and improved with longer-term versus short-term treatment $(p=0.015)$, possibly due to the anti-inflammatory properties of statins. A systematic review of statin use for the primary prevention of PSS and PSE by Nucera et al. [86] reported that one study showed reduced ASS risk and three studies showed reduced PSE risk with statin use following haemorrhagic cerebral infarction.

Other drugs, such as rapamycin, have antiepileptogenic mechanisms but have not yet been investigated in PSE [87]. The glutamate receptor antagonist PER was able to prevent the overactivity of glutamate receptors and block ischaemic pathological long-term potentiation. The neuroprotective antiseizure effects of PER could be observed at very low doses. Zonisamide showed similar neuroprotective effects to PER [88].

\section{Current research approaches}

Imaging of post-stroke glutamate-mediated excitotoxicity

The importance of thrombolysis for the primary prevention of PSS requires further clarification. Persistent neurological clinical deficits following thrombolysis (rather than the initially presenting deficits) are associated with a worse outcome and are independently associated with PSS or PSE [56]. Important questions remain to be investigated: Which mechanism is more relevant for epileptogenicity: the preservation of brain tissue by reperfusion or potential haemorrhagic transformation? Why does the outcome become less favourable when PSS occurs [18, 51]? Why do those with LS and a certain percentage of patients with ASS develop PSE? Animal models, such as the photothrombotic stroke model, provide a perspective for better understanding the mechanisms underlying epileptogenesis following cerebral infarction [89]. Through experimental models, changes can be analysed at the molecular and cellular levels and at the network level following stroke. Biomarkers can contribute to understanding the pathophysiology associated with PSS and improve risk assessment. Glutamate plays a significant role in epileptogenesis via post-stroke excitotoxicity, and the measurement of post-stroke glutamate concentrations may be useful [90]. The 7-Tesla chemical exchange saturation transfer (CEST) MRI method can be used to non-invasively measure glutamate (GluCEST) by indirectly measuring metabolite concentrations (e.g. glutamate) based on the energy transfer between hydrogen protons bound to the metabolite of interest and surrounding free water protons. A magnetically saturated, energetically excited state is induced in the metabolite-bound protons using a radiofrequency pulse shifted to the metabolite protons' resonance frequency to saturate the metabolite signal and reduce the MR signal. The spontaneous transfer of saturated protons to surrounding water results in a reduced MRI water signal proportional to the protons saturation quantity. The difference in water signal can be used as indirect evidence of metabolite concentration, such as glutamate. Repeated excitations increase the detectability of the molecule. As a proof of concept, an animal study showed a $100 \%$ increase in the GluCEST signal following middle cerebral artery occlusion [91].

Figure 2 shows the transfer of hydrogen protons and the resulting difference in the water signal as an indicator of glutamate concentration.

Another CEST analysis method uses a pH-weighted process to measure amide proton transfer signal intensity. In 55 patients with acute ischaemic infarct, the change in amide proton transfer signal intensity showed a good correlation $(p<0.001)$ with the NIHSS value and the 90-day modified Rankin scale (mRS) value $(p<0.001)$, 


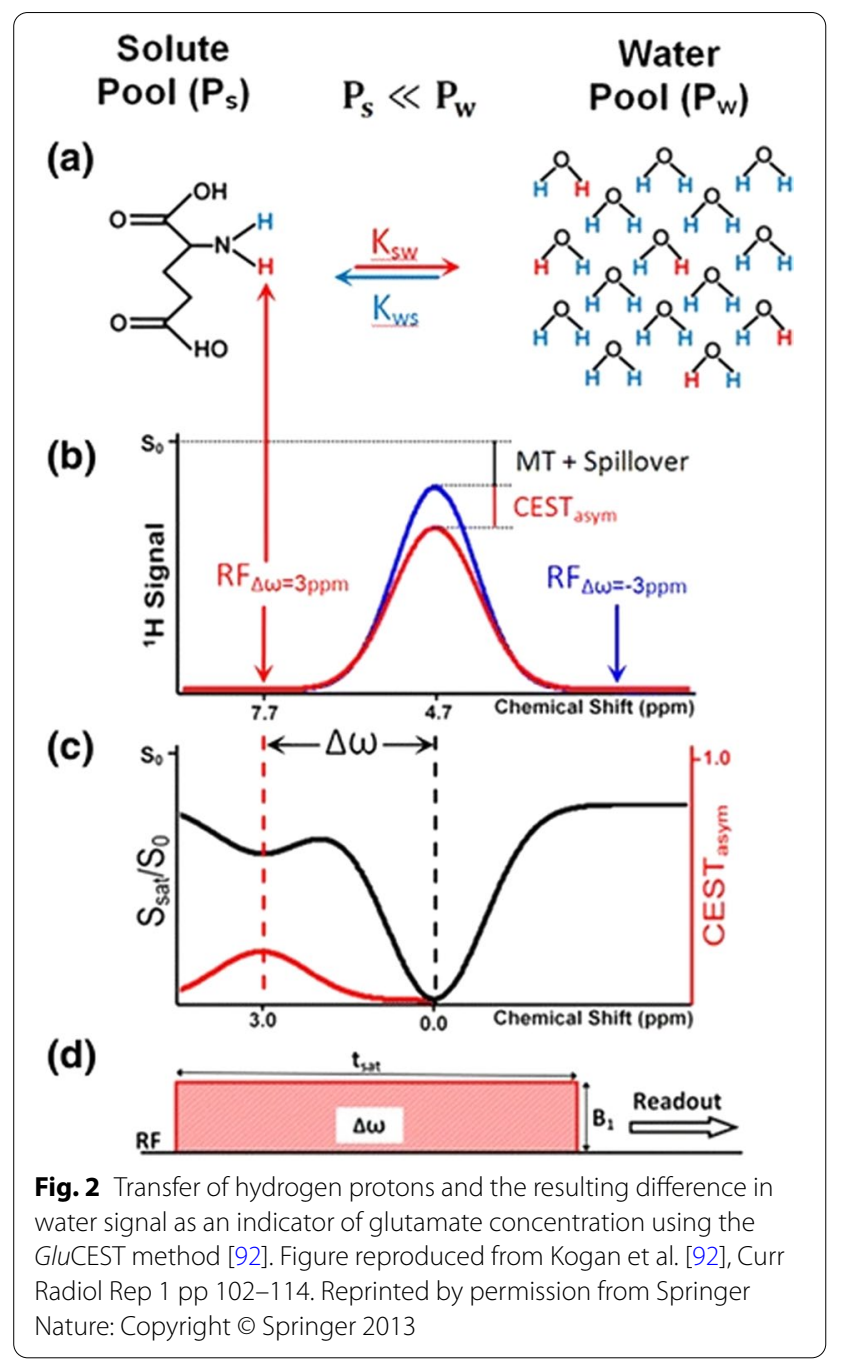

which may offer a method for estimating stroke severity and long-term prognosis (Fig. 3) [93].

To date, no unequivocal clinical evidence has been reported regarding the effectiveness of antiepileptic primary PSS prevention using medication. However, non-selective competitive $\alpha$-amino-3-hydroxy-5-methyl4-isoxazolepropionic acid (AMPA) receptor antagonists with glutamate-modulating effects, such as PER, represent possible antiepileptogenic and neuroprotective treatment options. GluCEST analyses may deliver further insights regarding the increased risk of PSS associated with increased glutamate signalling, whether antiglutamatergic agents can be used for primary PSS prevention purposes, and how the antiepileptogenic/neuroprotective effects of this approach compare against those associated with other drugs.

The relevance of biomarkers for risk assessment has been demonstrated through other research approaches. The evaluation of intracerebral bleeding using the
microRNA (miRNA) regulatory network as a potential biomarker for PSE confirmed that two miRNAs (4317 and 4315) are differentially expressed in PSE. The miRNA mi4317 regulates SCLC38A1, a glutamine-glutamate transporter [94]. The search for blood biomarkers that might be predictive for PSE confirmed known clinical risk factors, such as an NIHSS score of $\geq 8(p<0.001)$ and ASS occurrence $(p<0.001)$, and identified significant and independently associated serological markers, including an endostatin concentration $>1.23 \mathrm{ng} / \mathrm{ml}(p=0.046)$ and low concentrations of $\mathrm{S} 100 \mathrm{~B}$ and heat shock proteins $(\mathrm{Hsp} 70<2.496 \mathrm{ng} / \mathrm{ml}, p=0.006)$. The risk of PSE associated with combined supra-threshold values of these two biomarkers was $17 \%$. A combination of clinical and blood biomarkers further increases predicted risk [95]. These results complement prior findings exploring reduced tumour necrosis factor receptor 1 (TNF-R1) levels and increased levels of neural cell adhesion molecule (NCAM) as risk factors for post-stroke ASS [96]. NCAM is expressed on the pre- and post-synaptic membrane, where it mediates cell contacts between neurons and participates in the production of neurites and learning processes. NCAM is a danger-associated molecular pattern (DAMP) protein, which refers to a family of biomolecules that initiate inflammatory processes and are released during the neuroinflammatory phase. Another potential PSE biomarker is the polymorphism of acetaldehyde dehydrogenase 2 mitochondrial enzyme-rs671 (ALDH2-rs671) [97]. If confirmed, biomarker-based or combined clinical-biomarker based risk estimates could increase our ability to individually predict the occurrence of ASS and LS and thus contribute to the primary and secondary prevention of PSS.

\section{Blood-brain barrier dysfunction and post-stroke seizures}

The critical contribution of BBB dysfunction to the development of epileptic seizures and epilepsy has been widely acknowledged, although the mechanisms underlying epileptogenesis in pathologies associated with primary or secondary BBB damage are not completely understood [98, 99]. Among the mechanisms associated with BBB damage that might promote and maintain ictal activity at the cellular level, specific attention has been paid to the early astrocytic response to the extravasation of serum proteins, resulting in the activation of the innate immune system and altered potassium and glutamate homeostasis [99]. As a consequence of these changes, neuronal excitability is enhanced and potentially propagated via network connections [99]. Consistent with the link between $\mathrm{BBB}$ disruptions and epileptogenesis, DAMP protein levels, which serve as indicators of BBB dysfunction, are increased in stroke patients who later developed PSS [98, 100]. 


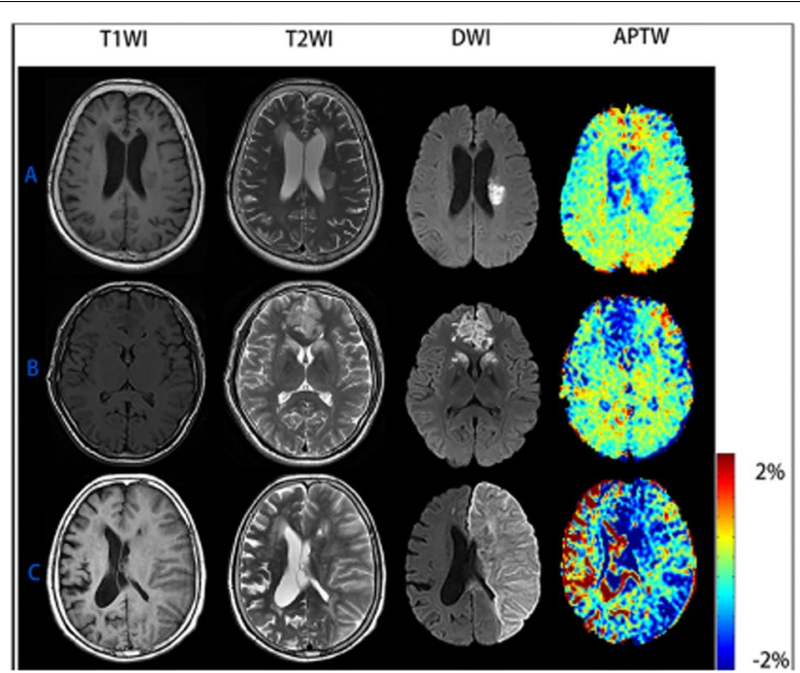

(A) M/65 years, NIHSS score was 3 and 90-day mRS score was $0, \triangle \mathrm{APTW}=-0.37 \%$

(B) F/69 years, NIHSS score was 5 and 90 -day mRS score was $2, \triangle$ APTW $=0.82 \%$.

(C) M/81 years, NIHSS score was 22 and 90 day $m R S$ score was $6, \triangle A P T W=1.93 \%$. The criterion for patient with good prognosis (mRS score $<2$ ) is $\triangle$ APTW $>-0.783$.

Fig. 3 Conventional structural MR images (T1- and T2-weighted imaging [T1WI/T2WI]) in the first and second column, diffusion-weighted image (DWI) in the third column, and amide proton transfer weighted imaging (APTW) in the fourth column from the left. Each row corresponds to images from an individual patient with acute ischaemic infarct and differing clinical reports [93]. Figure reproduced according to the Creative Commons Attribution (CC BY) license from: Lin et al. [93]. Copyright @ 2018 Lin, Zhuang, Shen, Xiao, Chen, Shen, Zong and Wu

Using MRI techniques, the occurrence of BBB disruption in acute ischaemic stroke has been increasingly investigated, particularly with regard to associated demographic and clinical factors, the impact of reperfusion therapies, and the prognostic relevance of BBB dysfunction for predicting haemorrhagic transformation and clinical outcomes after stroke [101]. For the assessment of $\mathrm{BBB}$ disruption in the setting of acute stroke, perfusionweighted imaging (PWI) is a particularly useful technique that can easily be incorporated into a standardised stroke imaging protocol and has been widely used [102-105]. The PWI approach that has traditionally been applied to the investigation of pathological changes in BBB permeability is dynamic contrast-enhanced imaging (DCE, often referred to as permeability imaging) and considers differences in the pre- and post-contrast T1-weighted images [102]. However, bolus-tracking dynamic susceptibility contrast imaging (DSC), which is included in standardised clinical stroke imaging protocols for the assessment of tissue-at-risk and therapeutic decision-making at many stroke centres [106], can also be employed to investigate BBB damage in acute stroke [105, 107], as the echoplanar imaging (EPI) sequences employed for DSC feature a mild T1-weighting in addition to being predominantly T2*-weighted [103, 105]. However, patients exhibiting a cerebral perfusion deficit, such as in acute stroke, require an arrival time correction for DSC-based permeability imaging to control for altered blood flow effects before calculating the permeability signal $[103,105]$. Both the DCE-PWI and delay-corrected DSC-PWI techniques to assess BBB permeability have successfully been applied successfully to investigate pre- and post-treatment $\mathrm{BBB}$ leakage in previous studies, which demonstrated associations between BBB disruption and haemorrhagic transformation, parenchymal haemorrhage, and unfavourable clinical outcomes [102, 104, 105, 107, 108] (Fig. 4). Furthermore, a high magnitude of BBB disruption correlates with the degree of hypoperfusion and is associated with poor collateral flow [102], whereas a favourable penumbral profile that predicts a favourable clinical outcome is associated with reduced BBB disruption [108]. As the clinical stroke severity influences the PSE risk, this suggests a link between BBB disruption and PSE. The findings of a recent study suggested that focal BBB leakage observed in acute ischaemic stroke may be transient and fully reversible after reperfusion [109]. Interestingly, using the DSC-PWI technique for BBB permeability imaging, Arba et al. showed significant $\mathrm{BBB}$ leakage in brain areas distal from the ischaemic lesion in acute ischaemic stroke patients with cerebral small vessel disease [110] and this suggests more wide-spread damaging that may be correlated with the generation of PSS. Alternative approaches for assessing BBB disruption in acute stroke include the measurement of the quantitative transverse relaxation time, $\mathrm{T} 2$, and the quantitative longitudinal relaxation time, T1. Quantitative T2 is generally sensitive to net water uptake and responds to the increased intracellular and interstitial fluid contents associated with acute stroke [111-114], whereas quantitative T1 is commonly regarded as a sensitive imaging marker for early and subtle BBB disruptions [115]. Previously, both techniques have been successfully implemented in 


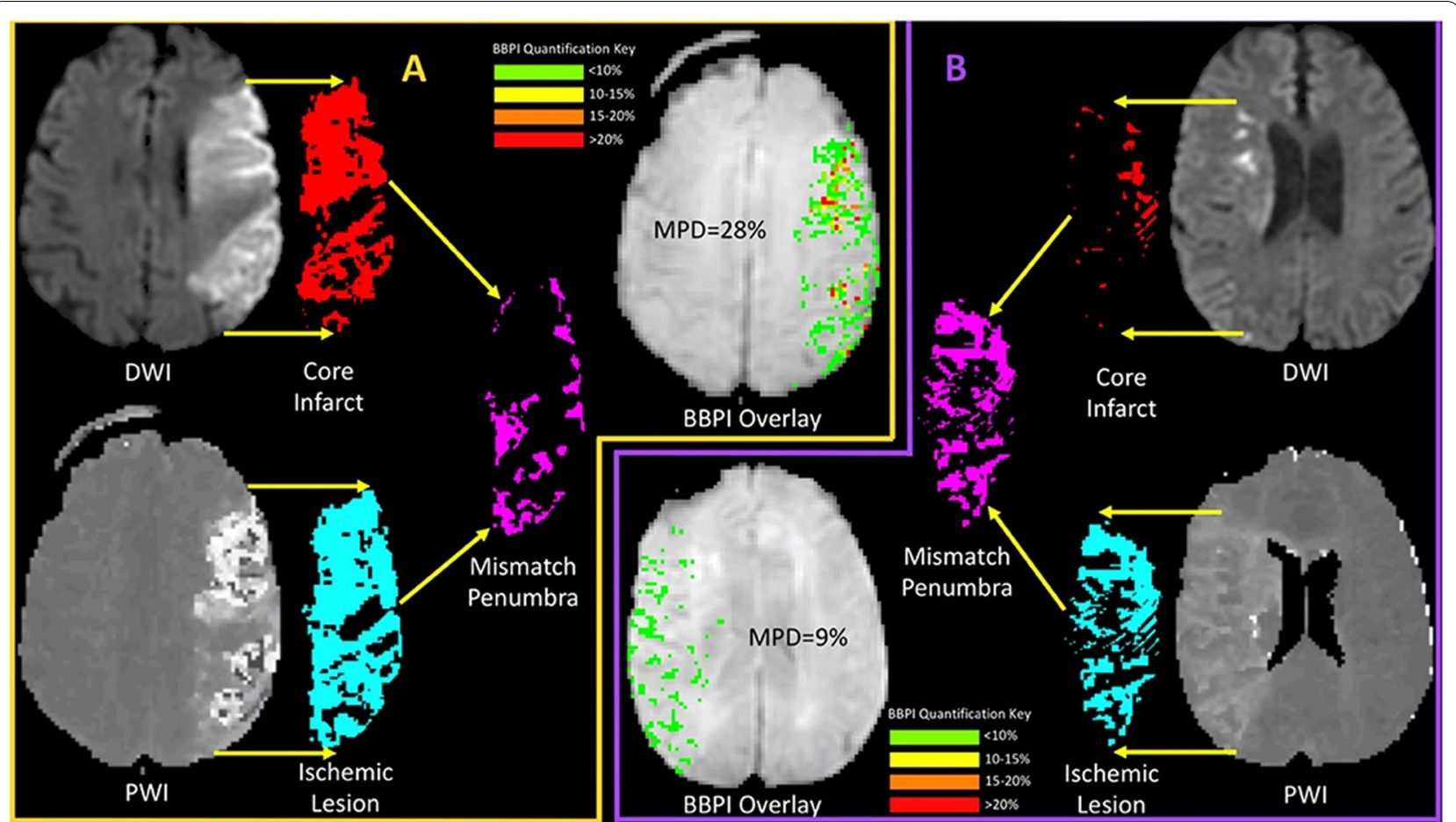

Fig. 4 Examples of blood-brain barrier permeability images using dynamic susceptibility contrast-enhanced perfusion-weighted imaging (DSC-PWI) showing the relative increase of BBB permeability in the area of ischemia compared to the corresponding area of the unaffected hemisphere (upper right image, respectively lower left image in $(\mathbf{a}, \mathbf{b})$ ) [108]. Figure reproduced according to the Creative Commons Attribution (CC BY) license from: Heidari et al. (2020). Copyright @ 2020 Heidari, Blayney, Butler, Hitomi, Luby and Leigh

acute stroke patients with reasonable acquisition times for clinical use [111-115]. Consequently, these MRI techniques might be promising candidates for the investigation of PSS and PSE and their associations with BBB leakage, potentially providing deeper pathophysiological insights that contribute to the identification of prevention and treatment strategies.

\section{Conclusions}

The complexity of stroke variables can complicate meaningful clinical trials. However, hypothesis-driven basic studies can pave the way for further research, and prospective, multicentre clinical studies examining large patient collectives with sufficiently standardised detailed information and case numbers to allow for subanalyses are also important. Methodologically sound randomisedcontrolled trials remain necessary to assess the importance of findings from both basic and observational research in the future.

The current state of PSE research can be summarised as follows:

1. More sophisticated epileptological questions are becoming increasingly important with improved stroke treatment and medical care, requiring detailed scientific investigations to better understand the risk factors associated with epileptogenesis.

2. Currently, no indication exists for the primary prevention of PSS using ASM. Indications for secondary PSS prevention using ASM should be individually determined based on patient characteristics and research findings. Unprovoked LS carry a recurrence risk resulting in PSE diagnosis, and ASM therapy should be offered in these cases. ASM with low pharmacological interaction potential should be preferred.

3. Therapy with rt-PA was initially contraindicated in cases of ASS and later reduced to a relative contraindication. Under individual consideration, ASS does not represent a contraindication to thrombolysis. Current clinical research in epileptology can thus inform the guidelines for stroke treatment.

4. New technologies, such as novel imaging and bloodbased biomarkers, may be suitable for assessing PSE risk and therapy effectiveness and open perspectives for further treatment optimisation in an expanding research area of high clinical relevance. 


\begin{abstract}
Abbreviations
AHA: American Heart Association; AMPA: a-Amino-3-hydroxy-5-methyl-4isoxazolepropionic acid; APTW: Amide proton transfer weighted imaging; ASA: American Stroke Association; ASM: Anti-seizure medication; ASS: Acute symptomatic seizure; AT1: Angiotensin-type 1 receptor; BBB: Blood-brain barrier; CBZ: Carbamazepine; CCA-IMT: Intima-media thickness of the common carotid artery; CEST: Chemical exchange saturation transfer; CRP: C-reactive protein; DAMP: Danger-associated molecular pattern protein; DCE-PWI: Dynamic contrast-enhanced perfusion-weighted magnetic resonance imaging; DOAC: Direct-acting oral anticoagulant; DSC-PWI: Dynamic susceptibility contrast perfusion-weighted magnetic resonance imaging; DWI: Diffusionweighted magnetic resonance imaging; ECG: Electrocardiogram; EHRA: European Heart Rhythm Association; EPI: Echoplanar imaging; ESL: Eslicarbazepine; ESO: European Stroke Organization; FDA: United States Food and Drug Administration; GBP: Gabapentin; IAT: Intraarterial thrombolysis; ILAE: International League Against Epilepsy; LCM: Lacosamide; LEV: Levetiracetam; LTG: Lamotrigine; LS: Late seizure; MRI: Magnetic resonance imaging; mRS: Modified Rankin Scale; MT: Mechanical thrombectomy; NCAM: Neural cell adhesion molecule; NCSE: Non-convulsive status epilepticus; NIHSS: National Institutes of Health Stroke Scale; OXC: Oxcarbazepine; PER: Perampanel; P-gp: P-glycoprotein; PHT: Phenytoin; PoSERS: Post-Stroke Epilepsy Risk Scale; PSE: Post-stroke epilepsy; PSS: Post-stroke seizure; PWI: Perfusion-weighted magnetic resonance imaging; rt-PA: Recombinant tissue plasminogen activator; SE: Status epilepticus; TGF $\beta$ : Transforming growth factor-beta; TNF-R1: Tumour necrosis factor receptor 1; VPA: Valproate; ZNS: Zonisamide.
\end{abstract}

\section{Acknowledgements}

Not applicable.

\section{Authors' contributions}

HS, JPZ, ASei, FR and AStr collected and analysed the data and prepared the manuscript. All authors (JPZ, FCS, FR, KK, ASei, AStr and HS) wrote the manuscript and revised it for content. All authors read and approved the final manuscript.

\section{Funding}

The authors were supported via the Center for Personalized and Translational Epilepsy Research (CePTER) with a LOEWE grant from the State of Hessen.

\section{Availability of data and materials}

Relevant data are publicly available from the literature sources. Data aggregated by the authors of this study is available upon reasonable request.

\section{Declarations}

\section{Ethics approval and consent to participate}

Due to the nature of the study (narrative review), there is no need for approval by an Ethics committee. No subjects or patients were included specifically for the purpose of this review.

\section{Consent for publication}

Not applicable.

\section{Competing interests}

JPZ received speakers' honoraria from Desitin Arzneimittel, GW Pharmaceuticals companies, and Eisai. FCS reports speakers' honoraria and travel cost or study reimbursements from Desitin Arzneimittel, Eisai, GW Pharmaceuticals companies, Medtronics, UCB Pharma, and Zogenix. FR reports personal fees and grants from Arvelle Therapeutics, Eisai GmbH, GSK, GW Pharmaceuticals companies, UCB Pharma, and MedilearnIndia. KK reports no conflicts of interest. ASei reports no conflicts of interest. AStr reports personal fees and grants from Arvelle Therapeutics, Desitin Arzneimittel, Eisai, GW Pharmaceuticals companies, Marinus Pharma, UCB, UNEEG medical, and Zogenix. HS received lecture honoraria and reimbursements for travel costs from Eisai and Desitin and advisory fees from Novartis. The authors did not perform any experiments on humans or animals for the purposes of this paper. The studies reported here were performed according to the guidelines reported therein.

\begin{abstract}
Author details
${ }^{1}$ Department of Neurology and Epilepsy Center Frankfurt Rhine-Main, Center of Neurology and Neurosurgery, Goethe-University Frankfurt, Schleusenweg 2-16, 60528 Frankfurt am Main, Germany. ${ }^{2}$ LOEWE Center for Personalized Translational Epilepsy Research (CePTER), Goethe-University Frankfurt, Frankfurt am Main, Germany. ${ }^{3}$ Department of Neurology, University Hospital Magdeburg, Magdeburg, Germany. ${ }^{4}$ Department of Neurology - Biomagnetism, University Hospital Erlangen, Erlangen, Germany.
\end{abstract}

Received: 16 August 2021 Accepted: 11 October 2021

Published online: 06 December 2021

\section{References}

1. Wang, J. Z., Vyas, M. V., Saposnik, G., \& Burneo, J. G. (2017). Incidence and management of seizures after ischemic stroke: Systematic review and meta-analysis. Neurology, 89(12), 1220-1228. https://doi.org/10.1212/ WNL.00000000000004407.

2. Zou, S., Wu, X., Zhu, B., Yu, J., Yang, B., \& Shi, J. (2015). The pooled incidence of post-stroke seizure in 102008 patients. Topics in Stroke Rehabilitation, 22(6), 460-467. https://doi.org/10.1179/1074935715Z. 00000000062

3. Holtkamp, M., Beghi, E., Benninger, F., Kälviäinen, R., Rocamora, R., \& Christensen, H. (2017). European Stroke Organisation guidelines for the management of post-stroke seizures and epilepsy. European Stroke Journal, 2(2), 103-115. https://doi.org/10.1177/2396987317705536

4. Won, S. Y., Konczalla, J., Dubinski, D., Cattani, A., Cuca, C., Seifert, V., Rosenow, F., Strzelczyk, A., \& Freiman, T. M. (2017). A systematic review of epileptic seizures in adults with subdural haematomas. Seizure, 45 , 28-35. https://doi.org/10.1016/j.seizure.2016.11.017

5. Won, S. Y., Dubinski, D., Sautter, L., Hattingen, E., Seifert, V., Rosenow, F., Freiman, T., Strzelczyk, A., \& Konczalla, J. (2019). Seizure and status epilepticus in chronic subdural hematoma. Acta Neurologica Scandinavica, 140(3), 194-203. https://doi.org/10.1111/ane.13131

6. Graham, N. S., Crichton, S., Koutroumanidis, M., Wolfe, C. D., \& Rudd, A. G. (2013). Incidence and associations of poststroke epilepsy: The prospective South London Stroke Register. Stroke, 44(3), 605-611. https://doi. org/10.1161/STROKEAHA.111.000220

7. Beghi, E., Carpio, A., Forsgren, L., Hesdorffer, D. C., Malmgren, K., Sander, J. W., Tomson, T., \& Hauser, W. A. (2010). Recommendation for a definition of acute symptomatic seizure. Epilepsia, 51(4), 671-675. https://doi. org/10.1111/j.1528-1167.2009.02285.x

8. Kim, H. J., Park, K. D., Choi, K. G., \& Lee, H. W. (2016). Clinical predictors of seizure recurrence after the first post-ischemic stroke seizure. BMC Neurology, 16, Article 212. https://doi.org/10.1186/s12883-016-0729-6

9. Hesdorffer, D. C., Benn, E. K., Cascino, G. D., \& Hauser, W. A. (2009). Is a first acute symptomatic seizure epilepsy? Mortality and risk for recurrent seizure. Epilepsia, 50(5), 1102-1108. https://doi.org/10.1111/j.15281167.2008.01945.x

10. Fisher, R. S., Acevedo, C., Arzimanoglou, A., Bogacz, A., Cross, J. H., Elger, C. E., Engel, J., Forsgren, L., French, J. A., Glynn, M., Hesdorffer, D. C., Lee, B., Mathern, G. W., Moshé, S. L., Perucca, E., Scheffer, I. E., Tomson, T., Watanabe, M., \& Wiebe, S. (2014). ILAE Official Report: A practical clinical definition of epilepsy. Epilepsia, 55(4), 475-482. https://doi.org/10.1111/ epi.12550

11. Qian, C., Löppönen, P., Tetri, S., Huhtakangas, J., Juvela, S., Turtiainen, H. M. E., Bode, M. K., \& Hillbom, M. (2014). Immediate, early and late seizures after primary intracerebral hemorrhage. Epilepsy Research, 108(4), 732-739. https://doi.org/10.1016/j.eplepsyres.2014.02.020

12. Winstein, C. J., Stein, J., Arena, R., Bates, B., Cherney, L. R., Cramer, S. C., Deruyter, F., Eng, J. J., Fisher, B., Harvey, R. L., Lang, C. E., MacKay-Lyons, M., Ottenbacher, K. J., Pugh, S., Reeves, M. J., Richards, L. G., Stiers, W., \& Zorowitz, R. D. (2016). Guidelines for Adult Stroke Rehabilitation and Recovery. Stroke, 47, e98-e169 https://doi.org/10.1161/STR.0000000000 000098

13. Zöllner, J. P., Konczalla, J., Stein, M., Roth, C., Krakow, K., Kaps, M., Steinmetz, H., Rosenow, F., Misselwitz, B., \& Strzelczyk, A. (2020). Acute symptomatic seizures in intracerebral and subarachnoid hemorrhage: A population study of 19,331 patients. Epilepsy Research, 161, Article 106286. https://doi.org/10.1016/j.eplepsyres.2020.106286 
14. Lahti, A. M., Saloheimo, P., Huhtakangas, J., Salminen, H., Juvela, S., Bode, M. K., Hillbom, M., \& Tetri, S. (2017). Poststroke epilepsy in long-term survivors of primary intracerebral hemorrhage. Neurology, 88(23), 2169-2175. https://doi.org/10.1212/WNL.0000000000004009

15. Lopponen, P., et al. (2014). Predictive value of C-reactive protein for the outcome after primary intracerebral hemorrhage. Journal of Neurosurgery, 121, 1374-1379. https://doi.org/10.3171/2014.7.JNS132678

16. Price, M., Gunther, A., \& Kwan, J. S. (2016). Antiepileptic drugs for the primary and secondary prevention of seizures after intracranial venous thrombosis. Cochrane Database of Systematic Reviews. https://doi.org/ 10.1002/14651858.CD005501.pub4

17. Guo, J., Guo, J., Li, J., Zhou, M., Qin, F., Zhang, S., Wu, B., He, L., \& Zhou, D. (2015). Statin treatment reduces the risk of poststroke seizures. Neurology, 85(8), 701-707. https://doi.org/10.1212/WNL.0000000000001814

18. Zöllner, J. P., Misselwitz, B., Kaps, M., Stein, M., Konczalla, J., Roth, C., Krakow, K., Steinmetz, H., Rosenow, F., \& Strzelczyk, A. (2020). National Institutes of Health Stroke Scale (NIHSS) on admission predicts acute symptomatic seizure risk in ischemic stroke: a population-based study involving 135,117 cases. Scientific Reports, 10, Article 3779. https://doi. org/10.1038/s41598-020-60628-9

19. Galovic, M., Döhler, N., Erdélyi-Canavese, B., Felbecker, A., Siebel, P., Conrad, J., Evers, S., Winklehner, M., von Oertzen, T. J., Haring, H. P., Serafini, A., Gregoraci, G., Valente, M., Janes, F., Gigli, G. L., Keezer, M. R., Duncan, J. S., Sander, J. W., Koepp, M. J., \& Tettenborn, B. (2018). Prediction of late seizures after ischaemic stroke with a novel prognostic model (the SeLECT score): a multivariable prediction model development and validation study. Lancet Neurology, 17(2), 143-152. https://doi.org/10. 1016/S1474-4422(17)30404-0

20. Strzelczyk, A., Haag, A., Raupach, H., Herrendorf, G., Hamer, H. M., \& Rosenow, F. (2010). Prospective evaluation of a post-stroke epilepsy risk scale. Journal of Neurology, 257(8), 1322-1326. https://doi.org/10.1007/ s00415-010-5520-9

21. Feyissa, A. M., Hasan, T. F., \& Meschia, J. F. (2019). Stroke-related epilepsy. European Journal of Neurology, 26(1), 18-e13. https://doi.org/10.1111/ ene.13813

22. Rumbach, L., Sablot, D., Berger, E., Tatu, L., Vuillier, F., \& Moulin, T. (2000). Status epilepticus in stroke: Report on a hospital-based stroke cohort. Neurology, 54(2), 350. https://doi.org/10.1212/wnl.54.2.350

23. Tsivgoulis, G., Alexandrov, A. V., Chang, J., Sharma, V. K., Hoover, S. L., Lao, A. Y., Liu, W., Stamboulis, E., Alexandrov, A. W., Malkoff, M. D., \& Frey, J. L. (2011). Safety and outcomes of intravenous thrombolysis in stroke mimics. Stroke, 42(6), 1771-1774. https://doi.org/10.1161/STROKEAHA 110.609339

24. Winkler, D. T., Fluri, F., Fuhr, P., Wetzel, S. G., Lyrer, P. A., Ruegg, S., \& Engelter, S. T. (2009). Thrombolysis in stroke mimics. Stroke, 40(4), 1522-1525. https://doi.org/10.1161/STROKEAHA.108.530352

25. Silverman, I. E., Restrepo, L., \& Mathews, G. C. (2002). Poststroke seizures. Archives of Neurology, 59(2), 195-201. https://doi.org/10.1001/archneur. 59.2.195

26. Redfors, P., Holmegaard, L., Pedersen, A., Jern, C., \& Malmgren, K. (2020). Long-term follow-up of post-stroke epilepsy after ischemic stroke: Room for improved epilepsy treatment. Seizure, 76, 50-55. https://doi. org/10.1016/j.seizure.2020.01.009

27. Trinka, E., Marson, A. G., van Paesschen, W., Kälviäinen, R., Marovac, J., Duncan, B., Buyle, S., Hallström, Y., Hon, P., Muscas, G. C., Newton, M., Meencke, H. J., Smith, P. E., \& Pohlmann-Eden, B. (2012). KOMET: an unblinded, randomised, two parallel-group, stratified trial comparing the effectiveness of levetiracetam with controlled-release carbamazepine and extended-release sodium valproate as monotherapy in patients with newly diagnosed epilepsy. Journal of Neurology, Neurosurgery \& Psychiatry, 84(10), 1138-1147. https://doi.org/10.1136/ jnnp-2011-300376

28. Gilad, R., Sadeh, M., Rapoport, A., Dabby, R., Boaz, M., \& Lampl, Y. (2007) Monotherapy of lamotrigine versus carbamazepine in patients with poststroke seizure. Clinical Neuropharmacology, 30(4), 189-195. https:// doi.org/10.1097/WNF.0b013e3180333069

29. French, J. A., Perucca, E., Sander, J. W., Bergfeldt, L., Baulac, M., Auerbach, D. S., Keezer, M., Thijs, R. D., Devinsky, O., Vossler, D. G., \&Welty, T. E. (2021). FDA safety warning on the cardiac effects of lamotrigine: An advisory from the Ad Hoc ILAE/AES Task Force. Epilepsia Open, 6(1), 45-48. https://doi.org/10.1002/epi4.12475
30. Belcastro, V., Costa, C., Galletti, F., Autuori, A., Pierguidi, L., Pisani, F., Calabresi, P., \& Parnetti, L. (2008). Levetiracetam in newly diagnosed lateonset post-stroke seizures: A prospective observational study. Epilepsy Research, 82(2-3), 223-226. https://doi.org/10.1016/j.eplepsyres.2008. 08.008

31. Belcastro, V., Pierguidi, L., \& Tambasco, N. (2011). Levetiracetam in brain ischemia: Clinical implications in neuroprotection and prevention of post-stroke epilepsy. Brain \& Development, 33(4), 289-293. https://doi. org/10.1016/j.braindev.2010.06.008

32. Consoli, D., et al. (2012). Levetiracetam versus carbamazepine in patients with late poststroke seizures: A multicenter prospective randomized open-label study (EplC project). Cerebrovascular Diseases, 34 282-289. https://doi.org/10.1159/000342669

33. Rosenow, F., Brandt, C., Bozorg, A., Dimova, S., Steiniger-Brach, B., Zhang, Y., Ferrò, B., Holmes, G. L., \& Kälviäinen, R. (2020). Lacosamide in patients with epilepsy of cerebrovascular etiology. Acta Neurologica Scandinavica, 141(6), 473-482. https://doi.org/10.1111/ane.13230

34. Belcastro, V., Vidale, S., Pierguidi, L., Sironi, L., Tancredi, L., Striano, P., Taborelli, A., \& Arnaboldi, M. (2013). Intravenous lacosamide as treatment option in post-stroke non convulsive status epilepticus in the elderly: A proof-of-concept, observational study. Seizure, 22(10), 905-907. https://doi.org/10.1016/j.seizure.2013.07.011

35. Fleet, J. L., Dixon, S. N., Kuwornu, P. J., Dev, V. K., Montero-Odasso, M., Burneo, J., \& Garg, A. X. (2018). Gabapentin dose and the 30-day risk of altered mental status in older adults: A retrospective population-based study. PLOS ONE, 13(3), Atricle e0193134. https://doi.org/10.1371/journ al.pone.0193134

36. Werhahn, K. J., Trinka, E., Dobesberger, J., Unterberger, I., Baum, P., Deckert-Schmitz, M., Kniess, T., Schmitz, B., Bernedo, V., Ruckes, C., Ehrlich, A., \& Krämer, G. (2015). A randomized, double-blind comparison of antiepileptic drug treatment in the elderly with new-onset focal epilepsy. Epilepsia, 56(3), 450-459. https://doi.org/10.1111/epi.12926

37. Marson, A., Burnside, G., Appleton, R., Smith, D., Leach, J. P., Sills, G., Tudur-Smith, C., Plumpton, C., Hughes, D. A., Williamson, P., Baker, G. A., Balabanova, S., Taylor, C., Brown, R., Howell, S., Hindley, D., Maguire, M., Mohanraj, M., \& Jauhari, P. (2021). The SANAD II study of the effectiveness and cost-effectiveness of levetiracetam, zonisamide, or lamotrigine for newly diagnosed focal epilepsy: an open-label, noninferiority, multicentre, phase 4, randomised controlled trial. The Lancet, 397(10282), 1363-1374. https://doi.org/10.1016/S0140-6736(21)00247-6

38. Alvarez-Sabín, J., Montaner, J., Padró, L., Molina, C. A., Rovira, R., Codina, A., \& Quintana, M. (2002). Gabapentin in late-onset poststroke seizures. Neurology, 59(12), 1991-1993. https://doi.org/10.1212/01.wnl.00000 38388.57824.b6

39. Sales, F., Chaves, J., McMurray, R., Loureiro, R., Fernandes, H., \& Villanueva, V. (2020). Eslicarbazepine acetate in post-stroke epilepsy: Clinical practice evidence from Euro-Esli. Acta Neurologica Scandinavica, 142(6), 563-573. https://doi.org/10.1111/ane.13323

40. Mazzocchetti, P., Mancini, A., Sciaccaluga, M., Megaro, A., Bellingacci, L., di Filippo, M., Cesarini, E. N., Romoli, M., Carrano, N., Gardoni, F., Tozzi, A., Calabresi, P., \& Costa, C. (2020). Low doses of Perampanel protect striatal and hippocampal neurons against in vitro ischemia by reversing the ischemia-induced alteration of AMPA receptor subunit composition. Neurobiology of Disease, 140, Article 104848. https://doi.org/10.1016/j. nbd.2020.104848

41. Ucar, M., Neuvonen, M., Luurila, H., Dahlqvist, R., Neuvonen, P. J., \& Mjörndal, T. (2004). Carbamazepine markedly reduces serum concentrations of simvastatin and simvastatin acid. European Journal of Clinical Pharmacology, 59(12), 879-882. https://doi.org/10.1007/ s00228-003-0700-5

42. Bialer, M., \& Soares-da-Silva, P. (2012). Pharmacokinetics and drug interactions of eslicarbazepine acetate. Epilepsia, 53(6), 935-946. https://doi. org/10.1111/j.1528-1167.2012.03519.x

43. Mintzer, S., Trinka, E., Kraemer, G., Chervoneva, I., \& Werhahn, K. J. (2018). Impact of carbamazepine, lamotrigine, and levetiracetam on vascular risk markers and lipid-lowering agents in the elderly. Epilepsia, 59(10),1899-1907. https://doi.org/10.1111/epi.14554

44. Galgani, A., Palleria, C., lannone, L. F., de Sarro, G., Giorgi, F. S., Maschio, M., \& Russo, E. (2018). Pharmacokinetic interactions of clinical interest between direct oral anticoagulants and antiepileptic drugs. Frontiers in Neurology, 9. https://doi.org/10.3389/fneur.2018.01067 
45. Berghuis, B., van der Palen, J., de Haan, G. J., Lindhout, D., Koeleman, B. P. C., \& Sander, J. W. (2017). Carbamazepine- and oxcarbazepine-induced hyponatremia in people with epilepsy. Epilepsia, 58(7), 1227-1233. https://doi.org/10.1111/epi.13777

46. Intravooth, T., Staack, A. M., Juerges, K., Stockinger, J., \& Steinhoff, B. J. (2018). Antiepileptic drugs-induced hyponatremia: Review and analysis of 560 hospitalized patients. Epilepsy Research, 143, 7-10. https://doi. org/10.1016/j.eplepsyres.2018.03.023

47. Zelano, J. (2016). Poststroke epilepsy: Update and future directions. Therapeutic Advances in Neurological Disorders, 9, 424-435. https://doi. org/10.1177/1756285616654423

48. Alvarez, V., Rossetti, A. O., Papavasileiou, V., \& Michel, P. (2013). Acute seizures in acute ischemic stroke: Does thrombolysis have a role to play? Journal of Neurology, 260, 55-61. https://doi.org/10.1007/ s00415-012-6583-6

49. Bentes, C., Martins, H., Peralta, A. R., Morgado, C., Casimiro, C., Franco, A. C., Fonseca, A. C., Geraldes, R., Canhão, P., Pinho E Melo, T., Paiva, T., \& Ferro, J. M. (2017). Epileptic manifestations in stroke patients treated with intravenous alteplase. European Journal of Neurology, 24(6), 755-761. https://doi.org/10.1111/ene.13292

50. Rodan, L. H., Aviv, R. I., Sahlas, D. J., Murray, B. J., Gladstone, J. P., \& Gladstone, D. J. (2006). Seizures during stroke thrombolysis heralding dramatic neurologic recovery. Neurology, 67(11), 2048-2049. https://doi. org/10.1212/01.wnl.0000247231.25231.2e

51. Alemany, M., Nuñez, A., Falip, M., Lara, B., Paipa, A., Quesada, H., Mora, P., de Miquel, M., Barranco, R., Pedro, J., \& Cardona, P. (2021). Acute symptomatic seizures and epilepsy after mechanical thrombectomy. A prospective long-term follow-up study. Seizure, 89, 5-9. https://doi.org/ 10.1016/j.seizure.2021.04.011

52. Brigo, F., Schneider, M., Wagenpfeil, G., Ragoschke-Schumm, A., Fousse, M., Holzhoffer, C., Nardone, R., Faßbender, K., \& Lochner, P. (2020). Intravenous thrombolysis with TPA and cortical involvement increase the risk of early poststroke seizures: Results of a case-control study. Epilepsy \& Behavior, 104, Article 106312. https://doi.org/10.1016/j.yebeh.2019.04. 056

53. Burneo, J. G., Antaya, T. C., Allen, B. N., Belisle, A., Shariff, S. Z., \& Saposnik, G. (2019). The risk of new-onset epilepsy and refractory epilepsy in older adult stroke survivors. Neurology, 93(6), e568-e577. https://doi. org/10.1212/WNL.0000000000007895

54. Naylor, J., Thevathasan, A., Churilov, L., Guo, R., Xiong, Y., Koome, M., Chen, Z., Chen, Z., Liu, X., Kwan, P., \& Campbell, B. C. V. (2018). Association between different acute stroke therapies and development of post stroke seizures. BMC Neurology, 18(1). https://doi.org/10.1186/ s12883-018-1064-X

55. Castro-Apolo, R., Huang, J. F., Vinan-Vega, M., \& Tatum, W. O. (2018). Outcome and predictive factors in post-stroke seizures: A retrospective case-control study. Seizure, 62, 11-16. https://doi.org/10.1016/j.seizure. 2018.09.007

56. Brondani, R., de Almeida, A. G., Cherubini, P. A., Secchi, T. L., de Oliveira, M. A., Martins, S. C. O., \& Bianchin, M. M. (2020). Risk factors for epilepsy after thrombolysis for ischemic stroke: A Cohort Study. Frontiers in Neurology, 10. https://doi.org/10.3389/fneur.2019.01256

57. Lekoubou, A., Fox, J., \& Ssentongo, P. (2020). Incidence and association of reperfusion therapies with poststroke seizures: A systematic review and meta-analysis. Stroke, 51(9), 2715-2723. https://doi.org/10.1161/ STROKEAHA.119.028899

58. Fridman, S., Burneo, J. G., \& Sposato, L. A. (2021). Letter by Fridman et al regarding article, "Incidence and association of reperfusion therapies with poststroke seizures: A systematic review and meta-analysis." Stroke, 52(1), e32-e33. https://doi.org/10.1161/STROKEAHA.120.032403

59. Gasparini, S., Ascoli, M., Brigo, F., Cianci, V., Branca, D., Arcudi, L., Aguglia, U., Belcastro, V., \& Ferlazzo, E. (2020). Younger age at stroke onset but not thrombolytic treatment predicts poststroke epilepsy: An updated meta-analysis. Epilepsy \& Behavior, 104, Article 106540. https://doi.org/ 10.1016/j.yebeh.2019.106540

60. Keller, L., Hobohm, C., Zeynalova, S., Classen, J., \& Baum, P. (2015). Does treatment with t-PA increase the risk of developing epilepsy after stroke? Journal of Neurology, 262, 2364-2372. https://doi.org/10.1007/ s00415-015-7850-0

61. Zöllner, J. P., Misselwitz, B., Mauroschat, T., Roth, C., Steinmetz, H., Rosenow, F., \& Strzelczyk, A. (2020). Intravenous thrombolysis or mechanical thrombectomy do not increase risk of acute symptomatic seizures in patients with ischemic stroke. Scientific Reports, 10, Article 21083. https://doi.org/10.1038/s41598-020-78012-y

62. De Reuck, J., \&Van Maele, G. (2010). Acute ischemic stroke treatment and the occurrence of seizures. Clinical Neurology and Neurosurgery, 112(4), 328-331. https://doi.org/10.1016/j.clineuro.2010.01.004

63. Nesselroth, D., Gilad, R., Namneh, M., Avishay, S., \& Eilam, A. (2018). Estimation of seizures prevalence in ischemic strokes after thrombolytic therapy. Seizure, 62, 91-94. https://doi.org/10.1016/j.seizure.2018.09.001

64. Kim, Y. H., Park, J. H., Hong, S. H., \& Koh, J. Y. (1999). Nonproteolytic neuroprotection by human recombinant tissue plasminogen activator. Science, 284(5414), 647-650. https://doi.org/10.1126/science.284.5414. 647

65. Tan, M. L., Ng, A., Pandher, P. S., Sashindranath, M., Hamilton, J. A., Davis, S. M., O'Brien, T. J., Medcalf, R. L., Yan, B., \& Jones, N. C. (2012). Tissue plasminogen activator does not alter development of acquired epilepsy. Epilepsia, 53(11), 1998-2004. https://doi.org/10.1111/j.1528-1167.2012. 03635.x

66. Lekoubou, A., Fox, J., \& Ssentongo, P. (2021). Response by Lekoubou et al to a letter regarding article "Incidence and association of reperfusion therapies with poststroke seizures: A systematic review and metaanalysis." Stroke, 52(1), e34. https://doi.org/10.1161/STROKEAHA.120. 032887

67. Steffel, J., Verhamme, P., Potpara, T. S., Albaladejo, P., Antz, M., Desteghe, L., Haeusler, K. G., Oldgren, J., Reinecke, H., Roldan-Schilling, V., Rowell, N., Sinnaeve, P., Collins, R., Camm, A. J., \& Heidbüchel, H. (2018). The 2018 European Heart Rhythm Association Practical Guide on the use of non-vitamin K antagonist oral anticoagulants in patients with atrial fibrillation. European Heart Journal, 39(16), 1330-1393. https://doi.org/ 10.1093/eurheartj/ehy136

68. von Oertzen, T. J., Trinka, E., \& Bornstein, N. M. (2019). Levetiracetam and non-vitamin K antagonist oral anticoagulants in patients with atrial fibrillation and epilepsy: A reasonable combination. European Heart Journal, 40(46), 3800-3801. https://doi.org/10.1093/eurheartj/ehz657

69. Mathy, F. X., Dohin, E., Bonfitto, F., \& Pelgrims, B. (2019). Drug-drug interaction between levetiracetam and non-vitamin $\mathrm{K}$ antagonist anticoagulants. European Heart Journal, 40(19), 1571. https://doi.org/10. 1093/eurheartj/ehy780

70. Kurt, S., Sumbul, O., \& Aksoy, D. (2019). Combination of non-vitamin K antagonist oral anticoagulants and antiepileptic drugs. European Heart Journal, 40(19), 1572. https://doi.org/10.1093/eurheartj/ehz091

71. Bodmer, M. (2006). Interaktionen zwischen Antiepileptika und kardiovaskulären Medikamenten. Epileptologie, 23, 8-13.

72. Kumral, E., Uncu, G., Dönmez, I., Cerrahoglu Sirin, T., Alpaydin, S., Çalli, C., \& Kitis, M. (2013). Impact of poststroke seizures on neurological deficits: Magnetic resonance diffusion-weighted imaging study. European Neurology, 69(4), 200-206. https://doi.org/10.1159/000345360

73. Mintzer, S., Skidmore, C. T., Abidin, C. J., Morales, M. C., Chervoneva, I., Capuzzi, D. M., \& Sperling, M. R. (2009). Effects of antiepileptic drugs on lipids, homocysteine, and C-reactive protein. Annals of Neurology, 65(4), 448-456. https://doi.org/10.1002/ana.21615

74. Chuang, Y. C., Chuang, H. Y., Lin, T. K., Chang, C. C., Lu, C. H., Chang, W. N., Chen, S. D., Tan, T. Y., Huang, C. R., \& Chan, S. H. H. (2011). Effects of long-term antiepileptic drug monotherapy on vascular risk factors and atherosclerosis. Epilepsia, 53(1), 120-128. https://doi.org/10.1111/j.15281167.2011.03316.x

75. Vyas, M. V., Davidson, B. A., Escalaya, L., Costella, J., Saposnik, G., \& Burneo, J. G. (2015). Antiepileptic drug use for treatment of epilepsy and dyslipidemia: Systematic review. Epilepsy Research, 113, 44-67. https:// doi.org/10.1016/j.eplepsyres.2015.03.002

76. Klein, P., Friedman, A., Hameed, M. Q., Kaminski, R. M., Bar-Klein, G., Klitgaard, H., Koepp, M., Jozwiak, S., Prince, D. A., Rotenberg, A., Twyman, R., Vezzani, A., Wong, M. \& Löscher, W. (2020). Repurposed molecules for antiepileptogenesis: Missing an opportunity to prevent epilepsy? Epilepsia, 61(3), 359-386. https://doi.org/10.1111/epi.16450

77. Löscher, W., Honack, D., \& Rundfeldt, C. (1998). Antiepileptogenic effects of the novel anticonvulsant levetiracetam (ucb L059) in the kindling model of temporal lobe epilepsy. Journal of Pharmacology and Experimental Therapeutics, 284(2), 474-479. 
78. Pitkänen, A., Roivainen, R., \& Lukasiuk, K. (2016). Development of epilepsy after ischaemic stroke. Lancet Neurology, 15(2), 185-197. https:// doi.org/10.1016/S1474-4422(15)00248-3

79. Takahashi, D. K., Jin, S., \& Prince, D. A. (2018). Gabapentin prevents progressive increases in excitatory connectivity and epileptogenesis following neocortical trauma. Cerebral Cortex, 28(8), 2725-2740. https:// doi.org/10.1093/cercor/bhx152

80. Cacheaux, L. P., Ivens, S., David, Y., Lakhter, A. J., Bar-Klein, G., Shapira, M., Heinemann, U., Friedman, A., \& Kaufer, D. (2009). Transcriptome profiling reveals TGF- $\beta$ signaling involvement in epileptogenesis. Journal of Neuroscience, 29(28), 8927-8935. https://doi.org/10.1523/JNEUROSCl. 0430-09.2009

81. Frigerio, F., Frasca, A., Weissberg, I., Parrella, S., Friedman, A., Vezzani, A., \& Noe', F. M. (2012). Long-lasting pro-ictogenic effects induced in vivo by rat brain exposure to serum albumin in the absence of concomitant pathology. Epilepsia, 53(11), 1887-1897. https://doi.org/10.1111/j.15281167.2012.03666.x

82. Bar-Klein, G., Cacheaux, L. P., Kamintsky, L., Prager, O., Weissberg, I., Schoknecht, K., Cheng, P., Kim, S. Y., Wood, L., Heinemann, U., Kaufer, D., \& Friedman, A. (2014). Losartan prevents acquired epilepsy via TGF- $\beta$ signaling suppression. Annals of Neurology, 75(6), 864-875. https://doi. org/10.1002/ana.24147

83. Hesdorffer, D. C., Stables, J. P., Hauser, W. A., Annegers, J. F., \& Cascino, G. (2001). Are certain diuretics also anticonvulsants? Annals of Neurology, 50(4), 458-462. https://doi.org/10.1002/ana.1136

84. Etminan, M., Samii, A., \& Brophy, J. M. (2010). Statin use and risk of epilepsy: A nested case-control study. Neurology, 75(17), 1496-1500. https://doi.org/10.1212/WNL.0b013e3181f96253

85. Li, Y., Zhang, B., Zhang, L., Xie, D., \& Li, Y. (2019). Efficacy of statin therapy in post-stroke seizure prophylaxis: Clues from an observational study of routine secondary prevention treatment. Seizure, 71, 185-189. https:// doi.org/10.1016/j.seizure.2019.07.010

86. Nucera, B., Rinaldi, F., Nardone, R., Lattanzi, S., \& Brigo, F. (2020). Statins in primary prevention of poststroke seizures and epilepsy: A systematic review. Epilepsy \& Behavior, 112, Article 107400. https://doi.org/10. 1016/j.yebeh.2020.107400

87. Sunnen, C. N., Brewster, A. L., Lugo, J. N., Vanegas, F., Turcios, E., Mukhi, S., Parghi, D., D'Arcangelo, G., \& Anderson, A. E. (2011). Inhibition of the mammalian target of rapamycin blocks epilepsy progression in NS-Pten conditional knockout mice. Epilepsia, 52(11), 2065-2075. https://doi. org/10.1111/j.1528-1167.2011.03280.x

88. Costa, C., Tozzi, A., Siliquini, S., Galletti, F., Cardaioli, G., Tantucci, M., Pisani, F., \& Calabresi, P. (2011). A critical role of NO/cGMP/PKG dependent pathway in hippocampal post-ischemic LTP: Modulation by zonisamide. Neurobiology of Disease, 44(2), 185-191. https://doi.org/10.1016/j.nbd. 2011.06 .015

89. Pitkänen, A., Kharatishvili, I., Karhunen, H., Lukasiuk, K., Immonen, R., Nairismägi, J., Gröhn, O., \& Nissinen, J. (2007). Epileptogenesis in experimental models. Epilepsia, 48(s2), 13-20. https://doi.org/10.1111/j. 1528-1167.2007.01063.x

90. Nicolo, J. P., O'Brien, T. J., \& Kwan, P. (2019). Role of cerebral glutamate in post-stroke epileptogenesis. Neuroimage Clinical, 24, Article 102069. https://doi.org/10.1016/j.nicl.2019.102069

91. Cai, K., Haris, M., Singh, A., Kogan, F., Greenberg, J. H., Hariharan, H., Detre, J. A., \& Reddy, R. (2012). Magnetic resonance imaging of glutamate. Nature Medicine, 18(2), 302-306. . https://doi.org/10.1038/nm. 2615

92. Kogan, F., Hariharan, H., \& Reddy, R. (2013). Chemical exchange saturation transfer (CEST) imaging: Description of technique and potential clinical applications. Current Radiology Reports, 1, 102-114. https://doi. org/10.1007/s40134-013-0010-3

93. Lin, G., Zhuang, C., Shen, Z., Xiao, G., Chen, Y., Shen, Y., Zong, X., \& Wu, R (2018). APT weighted MRI as an effective imaging protocol to predict clinical outcome after acute ischemic stroke. Frontiers in Neurology, 9. https://doi.org/10.3389/fneur.2018.00901

94. Iwuchukwu, I., Nguyen, D., Beavers, M., Tran, V., Sulaiman, W., Fannin, E., Lasseigne, L., Ramsay, E., Wilson, J., \& Bazan, N. G. (2020). MicroRNA regulatory network as biomarkers of late seizure in patients with spontaneous intracerebral hemorrhage. Molecular Neurobiology, 57(5), 2346-2357. https://doi.org/10.1007/s12035-020-01872-y
95. Abraira, L., Santamarina, E., Cazorla, S., Bustamante, A., Quintana, M., Toledo, M., Fonseca, E., Grau-López, L., Jiménez, M., Ciurans, J., Luis Becerra, J., Millán, M., Hernández-Pérez, M., Cardona, P., Terceño, M., Zaragoza, J., Cánovas, D., Gasull, T., Ustrell, X., ... Álvarez-Sabín, J. (2020). Blood biomarkers predictive of epilepsy after an acute stroke event. Epilepsia, 61(10), 2244-2253. https://doi.org/10.1111/epi.16648

96. Abraira, L., Giannini, N., Santamarina, E., Cazorla, S., Bustamante, A., Quintana, M., Toledo, M., Grau-López, L., Jiménez, M., Ciurans, J., Becerra, J. L., Millán, M., Cardona, P., Terceño, M., Zaragoza, J., Cánovas, D., Gasull, T., Ustrell, X., Rubiera, M., .. Álvarez-Sabin, J. (2020). Correlation of blood biomarkers with early-onset seizures after an acute stroke event. Epilepsy \& Behavior, 104, Article 106549. https://doi.org/10.1016/j.yebeh. 2019.106549

97. Yang, H., Song, Z., Yang, G. P., Zhang, B. K., Chen, M., Wu, T., \& Guo, R. (2014). The ALDH2 rs671 polymorphism affects post-stroke epilepsy susceptibility and plasma 4-HNE levels. PLOS ONE, 9(10), Article e109634 https://doi.org/10.1371/journal.pone.0109634

98. Galovic, M., Ferreira-Atuesta, C., Abraira, L., Döhler, N., Sinka, L., Brigo, F., Bentes, C., Zelano, J., \& Koepp, M. J. (2021). Seizures and epilepsy after stroke: Epidemiology, biomarkers and management. Drugs \& Aging, 38(4), 285-299. https://doi.org/10.1007/s40266-021-00837-7

99. Friedman, A. (2011). Blood-brain barrier dysfunction, status epilepticus, seizures, and epilepsy: A puzzle of a chicken and egg? Epilepsia, 52(Suppl 8), 19-20. https://doi.org/10.1111/j.1528-1167.2011.03227.x

100. Wu, H., Brown, E. V., Acharya, N. K., Appelt, D. M., Marks, A., Nagele, R. G., \& Venkataraman, V. (2016). Age-dependent increase of blood-brain barrier permeability and neuron-binding autoantibodies in S100B knockout mice. Brain Research, 1637, 154-167. https://doi.org/10.1016/j. brainres.2016.02.026

101. Arba, F., Rinaldi, C., Caimano, D., Vit, F., Busto, G., \& Fainardi, E. (2021). Blood-brain barrier disruption and hemorrhagic transformation in acute ischemic stroke: Systematic review and meta-analysis. Frontiers in Neurology, 11. https://doi.org/10.3389/fneur.2020.594613

102. Potreck, A., Mutke, M. A., Weyland, C. S., Pfaff, J. A. R., Ringleb, P. A., Mundiyanapurath, S., Möhlenbruch, M. A., Heiland, S., Pham, M., Bendszus, M., \& Hoffmann, A. (2021). Combined perfusion and permeability imaging reveals different pathophysiologic tissue responses after successful thrombectomy. Translational Stroke Research, 12(5), 799-807. https://doi.org/10.1007/s12975-020-00885-y

103. Leigh, R., Jen, S. S., Varma, D. D., Hillis, A. E., \& Barker, P. B. (2012). Arrival Time Correction for Dynamic Susceptibility Contrast MR Permeability Imaging in Stroke Patients. PLoS ONE, 7(12), Article e52656. https://doi. org/10.1371/journal.pone.0052656

104. Leigh, R., Hitomi, E., Hutchison, R. M., \& Elkins, J. (2021). Post-stroke blood-brain barrier disruption predicts poor outcome in patients enrolled in the ACTION study. Journal of Neuroimaging, 31(4), 751-757. https://doi.org/10.1111/jon.12862

105. Leigh, R., Christensen, S., Campbell, B. C., Marks, M. P., Albers, G. W., \& Lansberg, M. G. (2016). Pretreatment blood-brain barrier disruption and post-endovascular intracranial hemorrhage. Neurology, 87(3), 263-269. https://doi.org/10.1212/WNL.0000000000002862

106. Wintermark, M., Albers, G. W., Alexandrov, A. V., Alger, J. R., Bammer, R., Baron, J. C., Davis, S., Demaerschalk, B. M., Derdeyn, C. P., Donnan, G. A Eastwood, J. D., Fiebach, J. B., Fisher, M., Furie, K. L., Goldmakher, G. V., Hacke, W., Kidwell, C. S., Kloska, S. P., Köhrmann, M., ... Warach, S. (2008). Acute Stroke Imaging Research Roadmap. AJNR American Journal of Neuroradiology, 29(5), 1621-1628. https://doi.org/10.1161/strokeaha. 107.512319

107. Leigh, R., Jen, S. S., Hillis, A. E., Krakauer, J. W., Barker, P. B., Albers, G. W., Davis, S. M., Donnan, G. A., Fisher, M., Furlan, A. J., Grotta, J. C., Hacke, W., Kang, D. W., Kidwell, C., Koroshetz, W. J., Lees, K. R., Lev, M. H., Liebeskind, D. S., Sorensen, A. G., . . Wintermark, M. (2014). Pretreatment bloodbrain barrier damage and post-treatment intracranial hemorrhage in patients receiving intravenous tissue-type plasminogen activator Stroke, 45(7), 2030-2035. https://doi.org/10.1161/STROKEAHA.114. 005249

108. Heidari, P., Blayney, S., Butler, J., Hitomi, E., Luby, M., \& Leigh, R. (2020). The relationship between penumbral tissue and blood-brain barrier disruption in acute stroke patients presenting in an extended time window. Frontiers in Neurology, 11. https://doi.org/10.3389/fneur.2020. 582994 
109. Simpkins, A. N., Dias, C., Leigh, R., Benson, R. T., Hsia, A. W., Latour, L. L., Luby, M., Lynch, J. K., Merino, J. G., Nadareishvili, Z., \& Warach, S. J. (2016). Identification of reversible disruption of the human blood-brain barrier following acute ischemia. Stroke, 47(9), 2405-2408. https://doi.org/10. 1161/strokeaha.116.013805

110. Arba, F., Leigh, R., Inzitari, D., Warach, S. J., Luby, M., \& Lees, K. R. (2017). Blood-brain barrier leakage increases with small vessel disease in acute ischemic stroke. Neurology, 89(21), 2143-2150. https://doi.org/10.1212/ WNL.0000000000004677

111. Seiler, A., Lauer, A., Deichmann, R., Nöth, U., You, S. J., Pfeilschifter, W., Singer, O. C., Pilatus, U., \& Wagner, M. (2018). Complete restitution of the ischemic penumbra after successful thrombectomy. Clinical Neuroradiology, 29(3), 415-423. https://doi.org/10.1007/s00062-018-0675-3

112. Siemonsen, S., Mouridsen, K., Holst, B., Ries, T., Finsterbusch, J., Thomalla, G., Ostergaard, L., \& Fiehler, J. (2009). Quantitative T2 Values Predict Time From Symptom Onset in Acute Stroke Patients. Stroke, 40(5), 1612-1616. https://doi.org/10.1161/STROKEAHA.108.542548

113. McGarry, B. L., Damion, R. A., Chew, I., Knight, M. J., Harston, G. W., Carone, D., Jezzard, P., Sitaram, A., Muir, K. W., Clatworthy, P., \& Kauppinen, R. A. (2020). A Comparison of T2 Relaxation-Based MRI Stroke Timing Methods in Hyperacute Ischemic Stroke Patients: A Pilot Study. Journal of Central Nervous System Disease, 12, Article 117957352094331. https:// doi.org/10.1177/1179573520943314

114. Sah, R. G., Nobakht, S., Rajashekar, D., Mouches, P., Forkert, N. D., Sitaram, A., Tsang, A., Hill, M. D., Demchuk, A. M., d'Esterre, C. D., \& Barber, P. A. (2019). Temporal evolution and spatial distribution of quantitative T2 MRI following acute ischemia reperfusion injury. International Journal of Stroke, 15(5), 495-506. https://doi.org/10.1177/1747493019895673
115. Muñoz Maniega, S., Chappell, F. M., Valdés Hernández, M. C., Armitage, P. A., Makin, S. D., Heye, A. K., Thrippleton, M. J., Sakka, E., Shuler, K., Dennis, M. S., \& Wardlaw, J. M. (2017). Integrity of normal-appearing white matter: Influence of age, visible lesion burden and hypertension in patients with small-vessel disease. Journal of Cerebral Blood Flow \& Metabolism, 37(2), 644-656. https://doi.org/10.1177/0271678X16635657

116. Kutlu, G., Gomceli, Y. B., Unal, Y., \& Inan, L. E. (2008). Levetiracetam monotherapy for late poststroke seizures in the elderly. Epilepsy \& Behavior, 13(3), 542-544. https://doi.org/10.1016/j.yebeh.2008.04.025

117. Tanaka, T., \& Ihara, M. (2017). Post-stroke epilepsy. Neurochemistry International, 107, 219-228. https://doi.org/10.1016/j.neuint.2017.02.002

118. Huang, Y. H., Chi, N. F., Kuan, Y. C., Chan, L., Hu, C. J., Chiou, H. Y., \& Chien, L. N. (2015). Efficacy of phenytoin, valproic acid, carbamazepine and new antiepileptic drugs on control of late-onset post-stroke epilepsy in Taiwan. European Journal of Neurology, 22(11), 1459-1468. https://doi. org/10.1111/ene.12766

119. Polymeris, A. A., Curtze, S., Erdur, H., Hametner, C., Heldner, M. R., Groot, A. E., Zini, A., Béjot, Y., Dietrich, A., Martinez-Majander, N., von Rennenberg, R., Gumbinger, C., Schaedelin, S., de Marchis, G. M., Thilemann, S., Traenka, C., Lyrer, P. A., Bonati, L. H., Wegener, S., ... Engelter, S. T. (2019). Intravenous thrombolysis for suspected ischemic stroke with seizure at onset. Annals of Neurology, 86(5), 770-779. https://doi.org/10.1002/ana. 25582

\section{Publisher's Note}

Springer Nature remains neutral with regard to jurisdictional claims in published maps and institutional affiliations.
Ready to submit your research? Choose BMC and benefit from:

- fast, convenient online submission

- thorough peer review by experienced researchers in your field

- rapid publication on acceptance

- support for research data, including large and complex data types

- gold Open Access which fosters wider collaboration and increased citations

- maximum visibility for your research: over 100M website views per year

At BMC, research is always in progress.

Learn more biomedcentral.com/submissions 